\title{
COMPARISON OF INMARSAT
}

\&

ATS3

SATELLITE COMMUNICATION

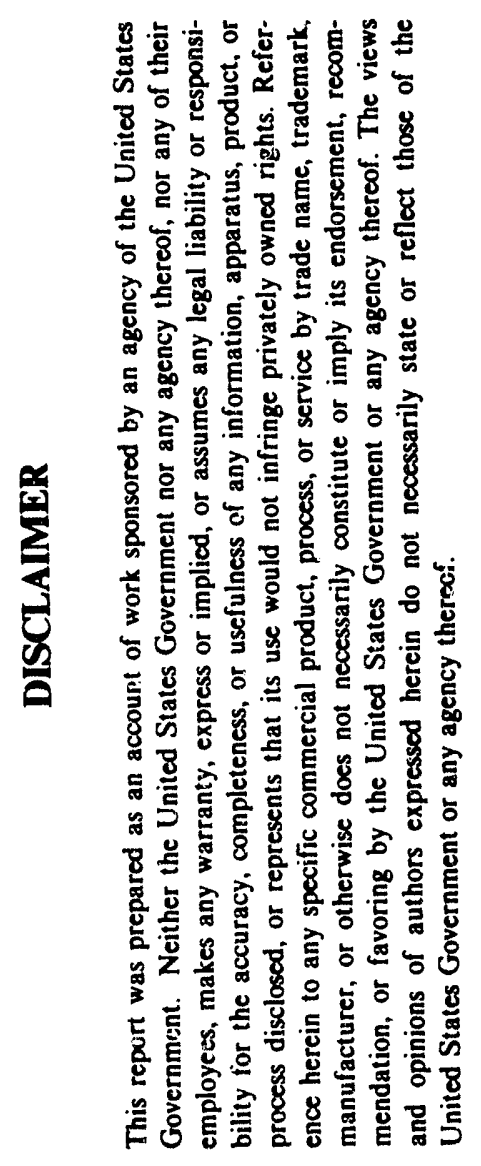

Contract No. 9-LV3-5192J-1

\author{
Prepared by: \\ Val Comm, Inc. \\ March 29, 1993
}

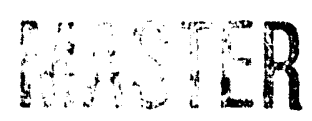




\section{TABLE OF CONTENTS}

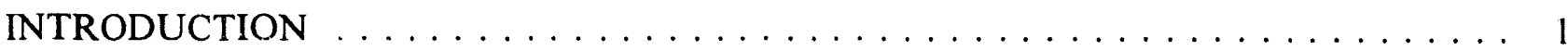

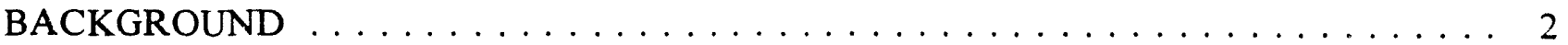

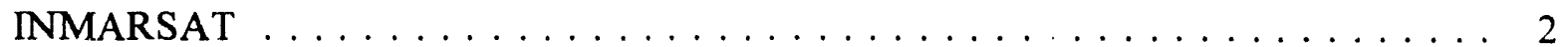

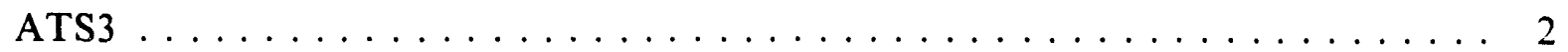

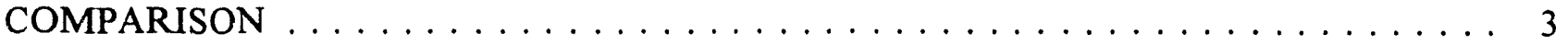

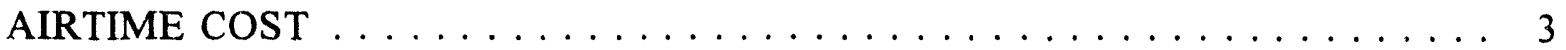

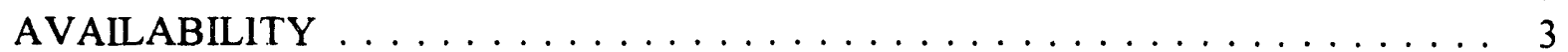

INMARSAT SUN-CYCLE $\ldots \ldots \ldots \ldots \ldots \ldots \ldots \ldots \ldots \ldots \ldots \ldots$

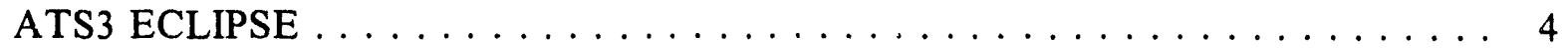

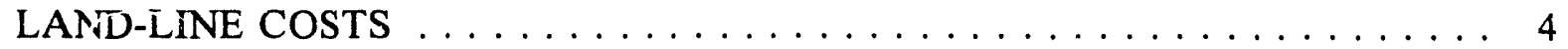

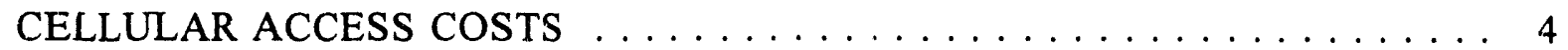

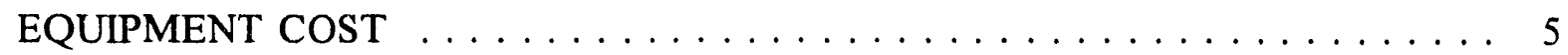

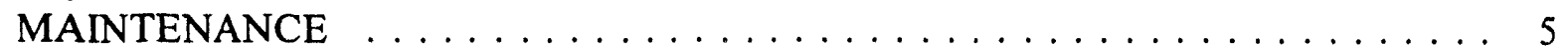

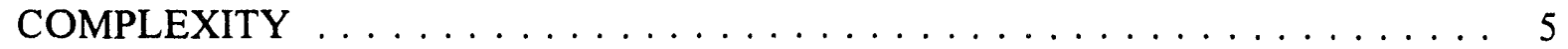

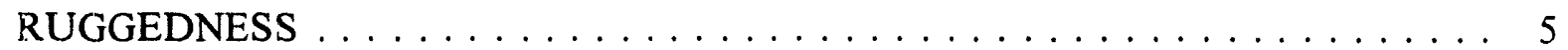

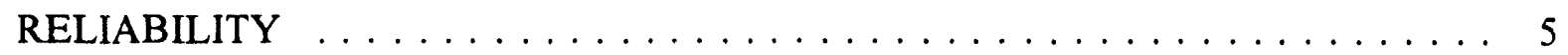

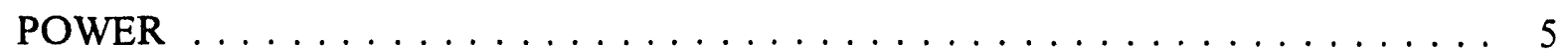

FREQUENCY BAND $\ldots \ldots \ldots \ldots \ldots \ldots \ldots \ldots \ldots \ldots \ldots \ldots \ldots \ldots \ldots \ldots \ldots$

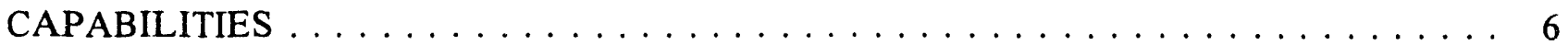

SUPPORTED FUNCTIONS $\ldots \ldots \ldots \ldots \ldots \ldots \ldots \ldots \ldots$

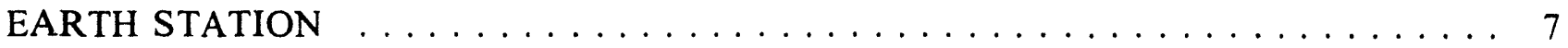

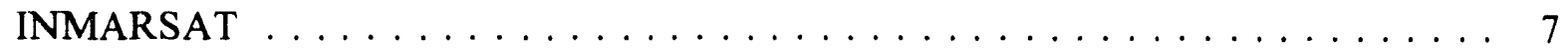

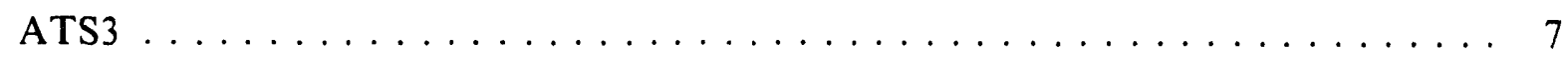

VOICE \& DATA CONCEPTS $\ldots \ldots \ldots \ldots \ldots \ldots \ldots \ldots \ldots \ldots \ldots$

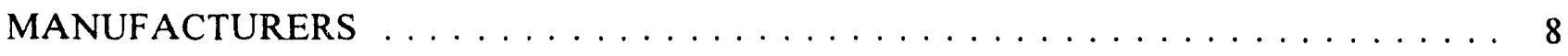

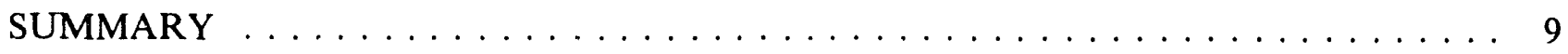




\section{INTRODUCTION}

There exists a need to provide communication through a satellite-based network which allows a user to communicate from a remote site to a fixed site. This discussion provides a comparison, both technical and financial, between the existing ATS3 satellite system and the commercial INMARSAT system. This comparison identifies the limitations of each system to provide various types of communication. 


\section{BACKGROUND}

\section{INMARSAT}

The INMARSAT (INternational MARitime SATellite) system is a commercial venture which was formed initially to provide dependable, 2-way voice communication from ships at sea. Its primary purpose, however, was to supply emergency communication channels for ships in distress. These functions are supported by a network of geo-stationary satellites over the major ocean regions of the world. By far the most pervasive (and the most lucrative) service has been the Standard-A or analog voice service. This service allows the sending and receiving of telephone calls aboard ships at sea.

The supported services have branched out to include wide-band computer-to-computer channels which support $56 \mathrm{~Kb}$ data rates. In addition, the system now supports a low bit rate digital message service (SeaMail) which operates in a store \& forward mode. This service, known as Standard-C, allows the transmission and reception of messages virtually anywhere in the world. A new digital voice service, Standard-M, is being implemented to provide a substantial increase to voice traffic capacity through the INMARSAT satellites. This service is scheduled to be fully operational by late 1993 .

All of the above services, except Standard-C, are designed for fixed platform operation. The antenna size requirements preclude operation in a moving land-based vehicle.

A typical Standard-A installation consists of a steerable antenna ( $\sim \mathrm{m}$ diameter) and a radio package. The entire installation typically fits within two suitcases and weighs approximately $75 \mathrm{lbs}$. Average power consumption during transmit is roughly 220 watts $\mathrm{AC}$ power. It should be noted that not all manufacturers offer DC power. It may be necessary to implement an inverter or generator for use in the field. The cost of a standard installation varies between $\$ 35,000$ to $\$ 50,000$.

\section{ATS3}

The ATS3 (Advanced Telecommunication Satellite) satellite system was originally launched by the National Aeronautics \& Space Administration (NASA) in 196\%. It was a forerunner of the earliest communication satellites and it provided a platform for many of the telecommunication research projects of the $70 \mathrm{~s} \& 80 \mathrm{~s}$. Originally inserted into a geosynchronous orbit, it has since run out of station-keeping fuel. Unlike today's commercial satellites which must seasonally adjust their orbits to coincide with the equator, the ATS3 satellite operates with an inclined orbit. To the ground observer, the satellite appears to sweep vertically over a 24 -hour period. This requires that an earth station be capable of tracking the $\pm 13^{\circ}$ vertical movement of the satellite.

ATS3 continues to supply basic radio communication functions in spite of its age and its tracking limitations. One of the early experiments involving the ATS3 satellite was the introduction of a spectrum conservation technique called ACSB (Amplitude Companded SideBand). It was found that a substantial amount of traffic could be added between the FM (Frequency Modulation) channels within the guard bands. In comparison to the primary FM 
channels, the guard bands utilize a severely restricted bandwidth. For simple voice traffic, the signal-to-noise ratios can be reduced, and smaller, less expensive earth station equipment can be used.

The ATS3 system is capable of supporting mobile-to-mobile data and voice communications in addition to providing a telephone platform for its mobile users. With relatively simple and inexpensive ACSB radio equipment, the mobile user can readily initiate and receive phone calls. A typical mobile configuration consists of an omni-directional mobile antenna (3dB Egg-Beater), a transceiver and DTMF (Dual-Tone Multi-Frequency) Touch-Tone' pad embedded within the microphone. The entire installation easily fits within half of a suitcase and weighs $18 \mathrm{lbs}$. Average power consumption during transmit is 240 watts DC. The cost of a typical mobile installation is roughly $\$ 3,000$.

The proposed site at Moriarty, NM consists of a $18 \mathrm{~dB}$ crossed yagi antenna array, an ACSB transceiver, DTMF decoder, phone patch and UPS (Uninterruptible Power Source). This configuration could support both mobile-to-base as well as phone access. (See Figure 1)

\section{COMPARISON}

The following information has been extracted from data acquired over the past three years. It represents a timely analysis of the current specifications and pricing. However, it should be pointed out that the information is based on both verbal and written data and is subject to change. The findings represent a comparison of only the INMARSAT Standard-A (Std-A) and ATS3 ACSB systems.

\begin{tabular}{||l|l|l|l||}
\hline & \multicolumn{1}{|c|}{ AIRTIME COST } & AVAILABILITY & \multicolumn{1}{c||}{ ECLIPSE } \\
\hline $\begin{array}{l}\text { INMARSAT } \\
\text { (Standard-A) }\end{array}$ & $\begin{array}{l}\text { Negotiable - \$6.50-\$15.00/Min. } \\
\text { (Portable-Portable doubles rate) } \\
\text { Different rates apply to peak } \\
\text { vs. off-peak hours }\end{array}$ & $\begin{array}{l}\text { 24-Hour subject } \\
\text { to emergency } \\
\text { blocking }\end{array}$ & $\begin{array}{l}\text { See INMARSAT } \\
\text { SUN-CYCLE }\end{array}$ \\
\hline $\begin{array}{l}\text { ATS3 } \\
\text { (ACSB) }\end{array}$ & $\begin{array}{l}\text { Airtime is free to validated } \\
\text { users }\end{array}$ & $\begin{array}{l}\text { 24-hour } \\
\text { availability } \\
\text { Non-interference } \\
\text { basis }\end{array}$ & $\begin{array}{l}\text { See ATS3 } \\
\text { ECLIPSE }\end{array}$ \\
\hline
\end{tabular}

INMARSAT has reduced its pricing for Standard-A airtime from $\$ 10 / \mathrm{Min}$ to $\$ 6.50 / \mathrm{Min}$ for government agencies. Negotiated rates can vary for non-government contracts. There is no

1 Touch-Tone is a registered trademark of American Telephone \& Telegraph Company 
minimum monthly maintenance charge, but most contracts for Std-A service have a negotiable minimum usage.

\section{INMARSAT SUN-CYCLE:}

There are short, predictable periods when earth-based INMARSAT receiving antennas will be required to look directly at the sun as it moves across the sky. During these periods the background noise increases dramatically, and all communication with the satellite is blocked. These solar cycles typically last for approximately 10 minutes and will occur for 3-4 days in a row. This phenomenon is due to the slow wobble or precession of the earth's rotation axis. This is the same wobble which accounts for the summer/winter seasonal changes.

\section{ATS3 ECLPSE:}

The ATS3 satellite is not truly geo-synchronous. That is, the orbit is not adjusted periodically to conform to the equator. This causes the satellite to appear to move vertically and return over a given 24-hour period. As the earth's wobble reaches its zenith, the additive affects of the satellite's inclined orbit and the earth's precession combine to place the line-of-sight link below the horizon for up to two hours in the day. This effectively blocks communication from specific sites. The winter eclipse began on $12 / 31 / 92$ through $04 / 30 / 93$ from $0620 \mathrm{Z}$ to $0800 \mathrm{Z}$. (Zulu time is MST minus $7 \mathrm{Hrs}$ or MDT minus $6 \mathrm{Hrs}$ )

\begin{tabular}{|l|l|l||}
\hline & \multicolumn{1}{|c|}{ LAND-LINE COSTS } & \multicolumn{1}{|c|}{$\begin{array}{c}\text { CELLULAR ACCESS } \\
\text { COSTS }\end{array}$} \\
\hline $\begin{array}{l}\text { INMARSAT } \\
\text { (Standard-A) }\end{array}$ & $\begin{array}{l}\text { Commercial toll charges } \\
\text { to/from Connecticut or } \\
\text { California earth stations } \\
\text { from/to recipient }\end{array}$ & $\begin{array}{l}\text { Commercial toll charges } \\
\text { to/from Connecticut or } \\
\text { California earth stations } \\
\text { from/to recipient }\end{array}$ \\
\hline $\begin{array}{l}\text { ATS3 } \\
\text { (ACSB) }\end{array}$ & $\begin{array}{l}\text { Commercial or FTS } \\
\text { charges to/from New Mexico } \\
\text { earth station from/to recipient }\end{array}$ & $\begin{array}{l}\text { Commercial or FTS } \\
\text { charges toll } \text { /from New Mexico } \\
\text { earth station from/to recipient }\end{array}$ \\
\hline
\end{tabular}

* Considerable savings may be realized by utilizing the FTS (Federal Telecommunication System) phone access in lieu of commercial phone access. 
COMPARISON OF INMARSAT (STANDARD-A) \& ATS3 (ACSB)

\begin{tabular}{||l|l|l||}
\hline & \multicolumn{1}{|c|}{$\begin{array}{c}\text { REMOTE SITE } \\
\text { EQUIPMENT COST }\end{array}$} & \multicolumn{1}{|c|}{$\begin{array}{c}\text { EARTH STATION } \\
\text { EQUIPMENT COST }\end{array}$} \\
\hline INMARSAT & $\begin{array}{l}\text { Std-A Remote Terminal: } \\
\sim 35,000-\$ 50,000\end{array}$ & $\begin{array}{l}\text { N/A - Switched phone service } \\
\text { normally provided by } \\
\text { INMARSAT }\end{array}$ \\
\hline ATS3 & $\begin{array}{l}\text { ACSB Remote Terminal: } \\
\sim 3000\end{array}$ & $\begin{array}{l}\sim 100,000 \text { including tracking } \\
\text { antenna and phone patch }\end{array}$ \\
\hline
\end{tabular}

Note: Tracking antennas are not necessary in New Mexico

The following comparison highlights the major differences between the INMARSAT Standard-A system and the ATS3 ACSB system.

\begin{tabular}{|c|c|c|c|}
\hline & $\begin{array}{c}\text { INMARSAT (Std-A) } \\
\text { REMOTE } \\
\text { TERMINAL } \\
\end{array}$ & $\begin{array}{c}\text { ATS3 (ACSB) } \\
\text { REMOTE } \\
\text { TERMINAL }\end{array}$ & $\begin{array}{c}\text { ATS3 (ACSB) } \\
\text { EARTH } \\
\text { STATION }\end{array}$ \\
\hline $\begin{array}{l}\text { HARDWARE } \\
\text { COST }\end{array}$ & $\begin{array}{l}\$ 35,000- \\
\$ 50,000 / \text { unit }\end{array}$ & $\sim \$ 3,000 /$ unit & $\sim \$ 100,000$ \\
\hline MAINTENANCE & $\sim \$ 5,000 /$ Yr/Unit* & & \\
\hline COMPLEXITY & Complex & Simple & Simple \\
\hline RUGGEDNESS & Very Rugged & Commercial Specs & Commercial Specs \\
\hline RELIABILITY & Highly Reliable & Highly Reliable & Highly Reliable \\
\hline $\begin{array}{l}\text { POWER } \\
\text { REQUIREMENTS }\end{array}$ & $\sim 220$ Watts AC & $\sim 240$ Watts DC & $\sim 240$ Watts DC \\
\hline $\begin{array}{l}\text { FREQUENCY } \\
\text { BAND }\end{array}$ & $1650 \mathrm{MHz}$ (L-Band) & $135-150 \mathrm{MHz}(\mathrm{VHF})$ & $135-150 \mathrm{MHz}(\mathrm{VHF})$ \\
\hline
\end{tabular}

* - Based on COMSAT estimates for shipboard Std-A terminals (Includes upgrades)

1 - INMARSAT Std-A terminals are not designed for use during inclement weather 


\section{CAPABILITIES}

\begin{tabular}{||l|l|l||}
\hline \hline & \multicolumn{1}{|c|}{$\begin{array}{c}\text { HALF-DUPLEX } \\
\text { SUPPORTED FUNCTIONS }\end{array}$} & \multicolumn{1}{c|}{$\begin{array}{c}\text { FULL-DUPLEX } \\
\text { SUPPORTED FUNCTIONS }\end{array}$} \\
\hline INMARSAT & $\begin{array}{l}\text { INMARSAT does not support } \\
\text { half-duplex operation }\end{array}$ & $\begin{array}{l}\text { Voice } \\
\text { Fax (up to Group III) } \\
\text { Data: } \\
\text { Dialup (up to 9600bps } \\
\text { without compression) } \\
\text { Dedicated(up to 56Kb) } \\
\text { Telex } \\
\text { Slo-Scan Video (56Kb) } \\
\text { Secure (STU-III) }\end{array}$ \\
\hline
\end{tabular}

\begin{tabular}{|c|c|c|}
\hline & $\begin{array}{c}\text { HAEN-DUPLEX } \\
\text { SUPPORTED FUNCTIONS } \\
\end{array}$ & $\begin{array}{c}\text { FULL-DUPLEX } \\
\text { SUPPORTED FUNCTIONS }\end{array}$ \\
\hline $\begin{array}{l}\text { ATS3 } \\
\text { (ACSB) }\end{array}$ & $\begin{array}{l}\text { Voice (Simplex Operation) } \\
\text { Limited Data ( } 4800 \text { bps - } \\
\text { Packet Modem) } \\
\text { Receive \& Initiate Telephone } \\
\text { Calls using DTMF }\end{array}$ & $\begin{array}{l}\text { Voice } \\
\text { Fax* } \\
\text { Data } \\
\text { Slow-Scan Video* } \\
\text { Secure (STU-III) 2400bps } \\
\text { maximum baud rate* }\end{array}$ \\
\hline
\end{tabular}

* Technically possible, but yet to be proven at unknown additional cost

The normal utilization of ACSB on the ATS3 satellite involves the use of a single frequency allocation. This results in a half-duplex operation which supports a one-way transmission at any given time. Once the traffic has been sent in one direction, the roles reverse and the previous sender becomes the receiver. During voics traffic, for example, an operator simply releases the microphone button to receive. There is no simultaneous, bi-directional communication. This fact limits the use of bi-directional protocols such as those employed in fax machines, the STU-III encryption device and many error-correcting data protocols. While technically feasible, full-duplex operation involves the scheduling of two communication channels to support requisite capabilities.

The degree of reliability for the ATS3 satellite system is a function of the satellite link margin. Noise from nearby devices, such as terrestrial RF sources and public utilities, can severely limit the ability to make a connection through the satellite from both the earth station and the remote terminal. While the earth station normally enjoys the advantages of high-gain, crossed yagi antennas, band-pass filters, preamplifiers and low RF noise levels, the remote 
terminal may not. It is essential that the operators be aware of possible operational limitations.

The INMARSAT system relies on several satellites which cover a large portion of the conterminous United States. Earth stations exist on both the East and West coasts which access the public switched dial network. The East coast station provides access to the Atlantic Ocean Region (AOR) East and West satellites while the West coast station provides access to the Pacific Ocean Region (POR) satellite as well as the AOR West satellite. INMARSAT recently added the AOR West satellite to completely cover the US mainland and fill in a coverage gap between the POR and AOR East satellites. The ATS3 system, on the other hand, has a single satellite, and the user must provide and maintain an earth station which provides these same mainland US coverage.

\section{EARTH STATION}

\section{INMARSAT}

The earth stations necessary for access to the INMARSAT system are supplied and operated within the US by COMSAT, a commercial satellite service. These facilities are located on both coasts. The earth station antennas are typically large dishes with a diameter up to 11 meters. Each facility is a multi-million dollar network node which is used for virtually all of the coastal access required by INMARSAT.

\section{ATS3}

The ATS 3 fixed site is located approximately 6 miles North of Moriarty, NM. This facility is located in an area of New Mexico known for low RF noise. The earth station radio equipment and the DTMF phone patch hardware can be readily secured in this former FAA navigation facility. This facility consists of:
a. Antennae (4Tx-4Rx)
b. Antenna Towers
c. RF Cables
d. Transceiver
e. Amp ifiers
f. DTMF Activated Phone Patch
g. Uninterruptible Power Source (UPS)
h. XIT Grounding System

\section{VOICE \& DATA CONCEPTS}

The concepts of using DTMF for access to the telephone system is not a radically new procedure. Amateur radio systerns have been operating for many years with this concept. Data has also been transmitted over these networks using packet modems. Several reports were generated and operational tests conducted in the late 80 s for the US Air Force, Titan Technology and Sandia National Laboratories when ATS3 was being considered. Coast-coast 
tests of mobile-mobile communication was demonstrated. Several other agencies, including DEA, have since been assigned operational channels on ATS3 and routinely make use of the resource in the operations.

Attachment $\mathrm{C}$ is enclosed which details the efforts to design the present "egg-beater" antenna.

\section{INMARSAT ADD-ON HARDWARE}

The add-on market for INMARSAT hardware is extensive. There are devices which support both still and full-motion video as well as devices which support data, fax and secure voice transmissious. An abbreviated list is shown in the following table.

\begin{tabular}{||l|l|c||}
\hline \multicolumn{1}{|c|}{ ITEM } & \multicolumn{1}{|c|}{ MANUFACTURER } & COST \\
\hline $\begin{array}{l}\text { Video Codec (Video) } \\
\text { Still \& Motion }\end{array}$ & PictureTel Corp. & $\$ 40,000$ \\
\hline STU-III (Secure Voice) & AT\&T & $\sim \$ 14,000$ \\
\hline FAX & Multiple Manufacturers & $\sim \$ 1500$ \\
\hline Modem & Multiple Manufacturers & $<\$ 1000$ \\
\hline $\begin{array}{l}\text { Laptop Computer w/Comm } \\
\text { Software }\end{array}$ & Compaq & $\sim \$ 4,000$ \\
\hline
\end{tabular}

\section{MANUFACTURERS}

A list of known manufacturers for both INMARSAT Std-A and ACSB hardware is attached. (See Attachments A and B) These lists includes manufacturers which represent themselves as manufacturers of equipment, but are known to actually market another manufacturer's hardware under their own brand name. The OEM (Original Equipment Manufacturer) concept is fairly common in this industry, and it is difficult to make this determination without actually comparing hardware. 


\section{SUMMARY}

From a cost perspective, it is clear that INMARSAT is considerably more expensive to acquire and operate than the ATS3 approach. The major cost difference lies in the charges for airtime. The hourly charges for INMARSAT air time are not obvious to the operator, and there is a tendency to over-use the service without regard to cost. A typical charge for a government agency in New Mexico averages $\$ 20,000 /$ month. The Standard-A equipment is also more expensive and vastly more complicated.

The ATS3 approach, on the other hand, is much simpler, less expensive and easier to operate than the INMARSAT Standard-A system. The only technical question lies in the reliability of the ATS3 satellite. NASA, the National Aeronautics \& Space Administration has been operating the ATS3 satellite since its launch in 1967 and projects its remaining orbital life to be at least 25 years. Barring some orbital disaster, the satellite should continue operating beyond the year 2018. There is no reason to presume that the satellite will fail during this period. 


\title{
ATTACHMENT A
}

\author{
INMARSAT Std-A
}

MANUFACTURERS

1. ABB NERA a.s

Mr. Sigurd Th Helland

PO Box 91, N-1361

Billingstadsletta, Norway

Phone: +47 2 844-700

Fax: +472 844-621

Telex: 71721 UMEBN

2. Japan Radio Company Ltd.

Mr. Akayoshi Sumita - Executive Managing Director

Akasaka Twin Tower (Main)

17-22 Akasaka 2-Chome,

Minato-ku, Tokyo 107, Japan

Phone: (03) 584-8756

Fax: (03) 584-8891

Telex: 02425420 JRCTOK J

3. MAGNAVOX - NAVCOM

Mr. Mario Cid Fernandez

9 Brandywine Drive

Deerpark, NY 11729

Phone: 516-667-7710

Fax: 516-667-2235

Telex: 645744 NAVCOMNY DEER

4. Marconi

Mr. Malcolm Bain

Marconi Marine

Elettra House

Westway Chelmsford

Essex CM13BH, UK

Phone: (0245) 261-701

Fax: (0245) 358-776

Telex: 99228 MIMCHD G 
5. Mobile Telesystems Inc.

Mr. Shafiq A. Chaudhuri

300 Professional Drive

Gaithersbur, MD 20879

Phone: 301-590-8500

Fax: 301-590-8558

Telex: 901885

6. Sperry Marine, Inc.

Mr. Robert W. Stroh

Seminole Trail

Charlottesville, VA 22901

Phone: 804-974-2000

Fax: 804-974-2259

Telex: 82-2411 


\section{ACSB RADIO EQUIPMENT \\ MANUFACTURERS}

1. Aerotron, Inc.

Wally Strater

4901 Capital Blvd

Raleigh, NC 27604

Phone: 919-872-4400

Fax: 919-872-8751

SALES:

Aerotron-Repco, Inc Steve Penic

2400 Sand Lake Rd

Orlando, FL 32809

Phone: 407-856-1953

Fax: 407-841-0331

2. Stevens Engineering Associates (SEA)

7030 220th St. SW

Mountain Terrace, WA 98043

Phone: 206-771-2182 
ATTACHMENT C

ANTENNA DEVELOPMENT REPORT 


\section{Sandia National Laboratories}

date: January 10, 1989

Albuquerque. New Mexico 87185

10: Mr. Al Downey, ATS-3 Experiments Manager
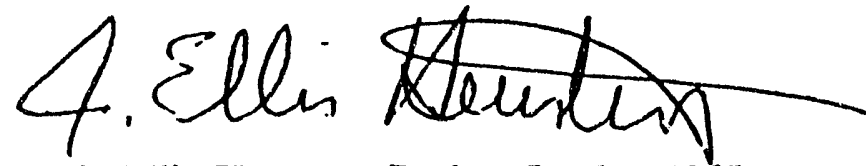

from: J. Ellis Heustess, Project Leader-5265

subject: Sandia National Laboratory Albuquerque ATS-3 Annual Test Report-1986/1987

\section{PURPOSE}

The primary purpose of using the ATS-3 Satellite during 1986 and 1987 was for Sandia National Laboratory Albuquerque (SNLA) and associated contractors to become familiar with the overall ATS-3 Satellite operations and to provide an antenna design suitable for mobile applications. A series of tests were conducted to determine the possible use of the NASA ATS-3 Satellite or a similar Satellite for voice communications by a Department of Energy (DOE) fleet during the transportation of nuclear products.

\section{ANTENNA DEVELOPMENT}

An antenna proposal was submitted to SNLA by Mr. Michael Staal, a consultant with VAL COMM. INC. His goal was to design a single, small, high efficiency, circular polarized antenna for reliable mobile to base communications through ATS-3. Mr. Staal was granted permission to proceed with the antenna design and the fabrication of prototypes. A copy of the antenna design report is included with this report. The antenna, now called the "eggbeater", is a standard VAL COMM. INC. product marketed to government agencies and also to radio amateurs. Data collected from the eggbeater antenna design and development has lead to other specific designs for portable ATS-3 antennas now in use by the Drug Enforcement Agency (DEA) in remote area locations in other countries.

\section{EARTH STATION NETWORK}

Five locations within the continental United States were chosen as operating sites. Those sites were: (1) Melbourne Village, Florida; (2) Bellevue, Washington; (3) Rochester, New York; (4) San Martin, California; and (5) Albuquerque, New Mexico. The sites were chosen primarily because a local contractor (VAL COMM, INC.) knew individuals in those areas that were willing to participate in the tests without charging SNLA for their time and efforts. Each test participant was furnished with the necessary equipment to support the test operations. All of the testing was coordinated through Mr. Paul Eden by Ellis Heustess and Emmett Sandoval of SNLA. Mobile operations from Albuquerque were coordinated by Mr. Mel Pfeffer of VAL COMM, INC. Mr. Pfeffer also provided a base station for monitoring the ATS-3 Satellite voice communications. 


\section{FM TESTS}

Neutec Model SP 1645 Transceivers with receiver preamplifiers and transmitter power amplifiers were procured, modified as necessary, and used for both base station and mobile operations. It was discovered early during testing that a base station with directional gain antennas would be required for continuing the experiments. Two base stations were installed, one located within SNLA and one located at VAL COMM. INC. The base station located within SNLA was not used as the primary base station because of power line noise and if interference from the military base and local airport. Interference during testing from mobile stations located in Mexico and other unknown areas of ten affected the test results. SNLA's time slot was also of ten compromised because of priority traffic from ships at sea and traffic from the South Pole. SNLA was willing to work under this restraint in order to obtain any useful information to be used during future test phases. Severe receiving problems were encountered by the mobiles located in the Northern Latitudes. Receiving the ATS-3 Satellite signals from the other mobiles in the SNLA network was often marginal. The Satellite could be heard when the Satellite reached its most Nurthern point. The FM tests were performed using the five earth stations as mobiles within their immediate areas. Two way communications tests were performed while the mobiles were in motion. Mobiles traveled in cities, small towns, remote areas, and on the open highways within their general home location. Base stations already in the ATS-3 system such as Malabar, Hawaii, and Arizona always reported good to excellent reports on reception of the SNLA FM mobile units. SNLA mobile units 1 through 5 were also successful in receiving Malabar which indicated that further enhancements for the SNLA base stations were needed.

Because of scheduling problems and other restraints, the FM tests were terminated. The FM transceivers were used only for monitoring satellite activity.

\section{ACSB TESTS}

Mr. Paul Eden advised SNLA that because of user time slot problems and heavy use of the ATS-3 Satellite for data transmission during SNLA's time slot that we (SNLA) should consider ACSB as a more efficient and convenient mode of operation. Stevens Model SEA 175 transceivers were procured and modified for ATS-3 operations. A companion solid state rf power amplifier was developed for specific use with the SEA 175 transceivers. Each transceiver was matched with an amplifier and adjustments were made to each transceiver/amplifier as a pair. Tests began to operationally test the equipment. At this point, the network was reduced to the Albuquerque base station and Albuquerque mobile station.

Mr. Paul Eden was instrumental in providing guidance to SNLA during the initial phases of these tests. The test results were somewhat improved over the FM tests. Our original approval for operating on the ATS-3 Satellite had lapsed and testing was terminated. 


\section{CONCLUSIONS}

Information gathered during the FM and ACSB test phases has produced a mobile antenna suitable for mobile operation. It became apparent that more sophisticated test equipment was required to establish more scientific test methods and evaluation procedures. Almost all of the expensive test equipment has now been procured. Thrse tests also impressed upon us that the base station location and base station antenia system should be improved in order to obtain system baseband information. Improvid base station transceivers, receiver preamplifiers, receiver bandpass filtērs, and variable $\mathrm{rf}$ power amplifiers are being investigated for use during the next ACSB testing phases. Forthcoming tests will be initiated to determine the following:

1) Signal to Noise Ratio (SNR) necessary for both mobile FM and ACSB operations.

2) Mobile antenna requirement for reception and transmit power necessary for successful ATS-3 operations.

3) Voice and data modes available for mobile operations.

4) Use of receiver preselectors and preamplifiers for mobile operations.

We, SNLA and VAL COMM, INC., believe that a mobile ACSB network may be possible and will work using a different philosophy during the next year. VAL COMM INC. has a more involved role in these experiments and has provided a test site approximately forty miles east of the greater Albuquerque metropolitan area that should provide a much quieter $r f$ noise environment than we used in the past. New base station antenna systems are currently being installed and several tests are now in process.

Enclosure: A'rS-3 MOBILE ANTENNA REPORT by Michael Staal

JEH:5265:jeh

Distribution:

Mr. Al Downey

ATS-3 Experiments Manager

Mail Stop 54-2

NASA LEWIS RESEARCH CENTER

21000 Brookpark Road

Cleveland, Ohio 44135

$(216) 433-4000$

Mr. Mel Pfeffer

President, VAL COMM, INC.

249 Muriel NE

Albuquerque, New Mexico 87123

5265 Larry G. Stotts

5265 Emmett L. Sandoval

5265 J. Ellis Heustess 
Mr. Michael A. Cauley

ATS-3 Experiments Manager

Mail Stop 54-2

NASA Lewis Research Center

Cleveland, Ohio 44135

Dear Mr. Cauley:

I would like to request the use of NASA's ATS-3 Satellite for one year (February 1, 1990 through January 31, 1991 ) to continue experiments with Amplitude Compandored Single Sideband (ACSB) modulation techniques. Sandia National Laboratories (SNL) continues to support the Department of Energy but also has other government agencies interested in the short-term use of low baud rate data being transferred using ACSB.

Channel assignments have already been coordinated through our local SNL frequency coordinator, with Mr. Paul Eden, and yourself. If additional coordination is required or channel assignments have changed, please advise us and we will adjust testing schedules accordingly.

I am currently compiling the 1989-1990 activity report for you and will forward it to as soon as possible. I believe that you already have received documentation from our contractor ( VAL COMM, INC. ) on most of the tests performed during the past year.

SNL and VAL COMM, INC. appreciates the concern and help provided from you personally during the past year and look forward to continuing working with you. There will probably be a few months of lag time before testing begins because of budget delays.

Thank you again for your patience and cooperation in this effort. If additional is required, please contact me. 


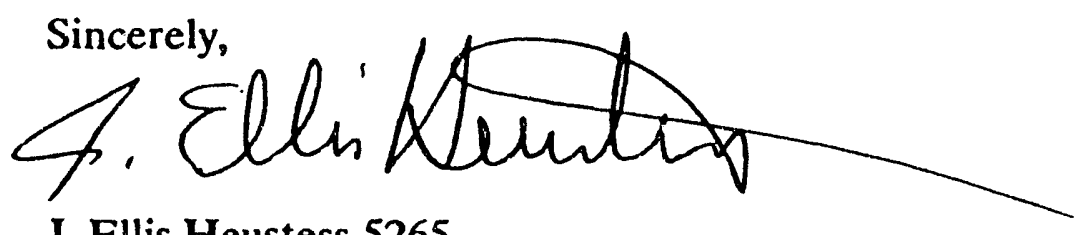

J. Ellis Heustess-5265

Communications Systems Division

Sandia National Laboratories

P.O. Box 5800

Albuquerque, NM 87185

Phone: 505-845-8324, FTS: $845-8324$

\section{JEH:5265:jeh}

Copy to:

5265 Larry G. Stotts

5265 Emmett L. Sandoval

5265 Robert Trudo

5265 J. Ellis Heustess

VAL COMM, INC. Attn: Paul Rael 
ATS-3 MOEILE ANTENNA REPORT OCt.6, 1986
EY Mictiael StaAl

Desigr, Gaal: Ta desigr, a sirigle, small, high efficiericy circular polarized antenna for reliable mobile to base commurications through ATS-3

The special problems related ta this gaal iriclude a ten percerit mirimum bandwidth requirement for the anterina while trying ta hold a gcicid match, gciad circularity arid riear peak gairi civer that frequericy spread (uplink 149.220 and downlink $135.600 \mathrm{mHz}$ ). Eecause of the irifirite number of passible vehicle arientatiaris arid the wide longitude and latitude spread the continental United States presents, the aritenria must have a half sphere bearnwidth and ideally be circular polarized completely ir that sphere as well.

The ATS-3 satellite aritennas are uriforturiately liriear palarized or bath uplirik and downlink which mearis the already low gair ariterina mist also give up 3 dB more by being circular polarized. The reasor, the up/down link mabile arienna polarization must be circular because of the ever charging amount af electrans in the path betweer, the mobile urit and the sateliite. The actual arientaticr, cif the linear polarity preserited by the satelilte is totally raricin. This effect is called faraday motation. In the $140 \mathrm{Mh}=$ regicir the electror carterit has a dramatic effect or polarity orieriatior. Faraday rotation is frequericy sensitive arid mare polarity shift cocurs al i $36 \mathrm{mHz}$ thari at $149 \mathrm{mHz}$. This inearis polarizatiar orieritatior may be significarily different at the uplirik arid dciwrilirik frequericies.

A circular polarized ariterina can rullify the effects of faraday rectaticri if the ariterias is poiritirig directly at the satellite as base statiaris ariterias cari do. Unfortunately ir a mobile situaticir, the ariteria seldorn if ever pairis at the satelite as it must poirit straight up, perperdicular to the axis of the vehicle. The prablem here is that circular palarized ariterias are crily circular in twa directions, off the front arid off the back. Off axis they gerierate every conceivable mixture of liriear arid circular. Typically what is gerierated ir the directior of the satellite is mild ta severe elipticity.

To make matters worse, high derisity clouds of electroms in the sigrial path car eritarice or atteruate the sigrials sometimes iri excess of $10 \mathrm{~dB}$. This effect ever causes well equipped base staticirs with trackirig, high gairicircular polarized arteria systems to lase communicaticis from time to time. This effect is called sciritallatiori.

New, compound all the aforemeritioried problems with the fact the ATS-3 satelitite is rot in a gecosnchrarious orbit but an orbit that allciws it tci float above arid below the equatorial plarie as much as fifteer degrees. If the beamwidth arid the circularity were rict already stretched, this orbit pertubatior is the real test of the mobile ariterias performarice. 
So the reliablility of the mabile urits signals to and from the satellite are clearly not just a furictior cif free space path loss as much as its geomagrietic latitude, seasor of the year, $t$ ime of day, pointirig directior and location of the satellite, icrispheric disturbarices, and the variations ir the satellites pciwer mode(max.47.6 dEm ard min.39.8 dBm). In addition the satellite exhibits output power jumps of 1 to 2 dE wher the input sigrial is weak. Firially, terrestrial iriterfererice both or the input frequericy and at the output can further reduce the mabile urits perceritage of commurication reliability.

DESIGN SEARCH

Many anterina types were irivestigated. Preserited here are the few that appear to have enough useful qualifications to be worthy of further commerit.

Crossed dipoles over a reflective plare preserit a low profile but good circularity is difficult to achieve at one frequency much less cover 10\% baridwidth. Gain is expected to be approximately 4 dbc on axis and at center frequency which will be less arid legs as the latitude of the ariteriras is increased. Qverall estimated usable gain is - ZdB. This gain number is a result of typical off axis headirig due ta latitude lacatiori, frequericy compromise between transmit arid receive and nor circular antennas on the spacecraft.

Helix ariteririas are broadbarid but scinewhat bulky arid they darit gerierate gaod circularity with just orie to two turris. Expected gain is 4dbc but the actual usable gain again due to the above noted factars other than frequercy compromise is $-1 \mathrm{~dB}$.

Crossed full wave lacips carnmorily called ari "eggbeater" anterina was finally chaser as having the best charice to meet all the requiremerits. While slightly bulky it exhibits a hernispherical patterr wher placed $1 / 8$ wave over a reflective surface and is very circular off the tap. The $10 \%$ baridwidth requiremerit is also passible with this anterina but its circularity suffers when it is used over the 10\% bandwidth. Structurally it is sciurid arid has been used for onridirectional, horizontally polarized mobile ariterias for many years. Its gair over a reflective surface is $4 d B c$ and the expected gair because of the aforementioned factors is 0 dbc. See figure 1 .

Duririg early eggbeater testing it was reasoried that the eggbeater was probably wasting some of its performarice by allowing cansiderable pawer ta radiate belcw zo degrees above the horizor. Addirig bearn focusing elemerits like a director to the already 39. irich structure seemed pciritless so the lower profile crossed dipoles over a plare reflector lcoked like ar obvicus choice or which ta try directars.

A secorid ariterira was built utilizing the same balur, a slightly longer phasing harness optimized at the receive frequency and the same physical structure as the eggbeater but this time the full wave lacips were replaced with folded dipoles. See figure $z$. 
Pattern and gain tests were run and it was again found that $1 / 8$ wavelength spacirig abcive the reflective plarie gave the best overall performarice arid match characteristics. Directors were now added while the gain of the anterira was rf swept to watch the gain baridwidth. Very short directors were the firial choice since they had to furiction as directars at 149. 2e mHz. Loriger directors produced more receive gain but looked like reflectors at the trarismit frequericy (149. $2 \mathrm{~m} \mathrm{mHz})$.

Qverall this riew structure was still lower profile (21") thar the eggbeater arid produced mare gair off the tap with corisiderably less gain below 20 degrees above the horizon. This new antenna was tested for several days through ATS-3 and or all but orie accasion outperformed the eggbeater. It appeared the tests through the satelitite had produced the same results as the original short rarige tests proved. Even though the circularity was not as good, the added sigral margin overcame the elipticity. The initial tests were carried out from two California locations; 37 arid 30 degrees ricirth latitude.

Keep in mind that the signals through the satellite were $F M$ whose characteristics are such that orice threshald is reached, large signal to noise improvemerits are noted for orily a $\triangle B$ or so more sigrial.

With the early results showirg promise, folded dipole/directar kits were sent to the ather test participaris in New york, Florida, Washirigtor state arid New Mexica. To date, mixed results have been obtairied. Orily at the New Mexico location was the crassed dipole/director systern "better" thar the eggbeater, however severe elipticity was roted arid caused loss of receive in certain mobile orieritatioris. This cariditich was probably caused by the fact that the origirial eggbeater phasing section was cut ta praduce perfect circularity at the trarisinit frequericy arid riat at the receive frequency as ir the first test unit.

The perfarmarice of the "eggbeater" is consisterit with what orie might expect of a law gair ariterina with ar almost perfect hérnispherical patterr. Day to day checks iridicate the most consistericy of ariy of the anteririas tested. Some narrower bearnwidth ariterivas performed better on days that the satelite was above the equatorial plane, but much worse wher the satellite dipped below the plarie.

Recently tests were resumed at the ricorthern Califorria latitude (37 degrees) ard this time the results were dramatically differerit. No access to the satelitite could be accomplished with the crossed dipcile/director ariterira uriless it was $t$ ilted toward the satelitite at about 35 degrees above the horizor. The eggbeater or the cither hard perfarmed as usual by achieving partial $\mathrm{FM}$ quietirig adequate for $100 \%$ but difficult readibility. No tilting of the eggbeater was required nor was readability improved by pairitirig at the satellite. The orly thirig that was improved by tiltirig toward the satelilite was a reduction of elipticity as the eggbeater was rotated 360 degrees or axis which 
was to be expected. Apparerity, for the first set of test days and $t$ imes the satellite had always been either at the equatorial plarie or abcive it. best of all and combine thase feachosen for profile arid the ariterinas. Folded dipoles $149.2 e$ and two at $135.6 \mathrm{mHz}$, will be four dipoles, two at prabably 10 to 12 iriches over the vehicle oriented in a square prebad to produce circular polarity. Ore roof. Each pair wil for right hard circular and the other pair far set will gircular to attempt to minimize coupling and proximity cauld be added but careful positioning will be effects. Directars cculd be acod gain down to 20 degrees above the required

This configuration has other passibilities. If sufficient reason exists, automatic phase steering of this configuration could be accomplished ard the beam shift steps cauld be quite braad. Perhaps only two or three adjustmerits may be required. 
EGgbeater pattern
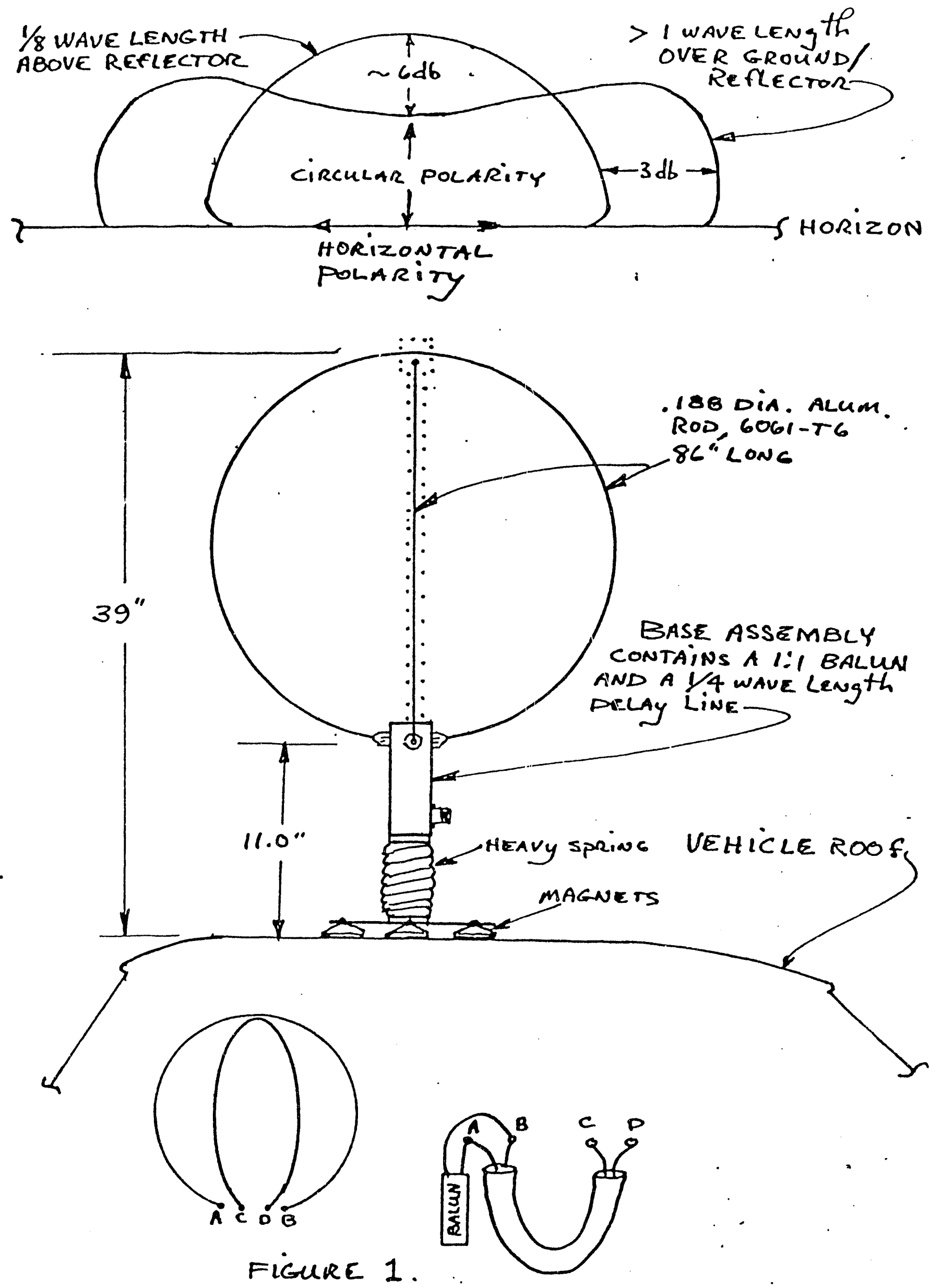

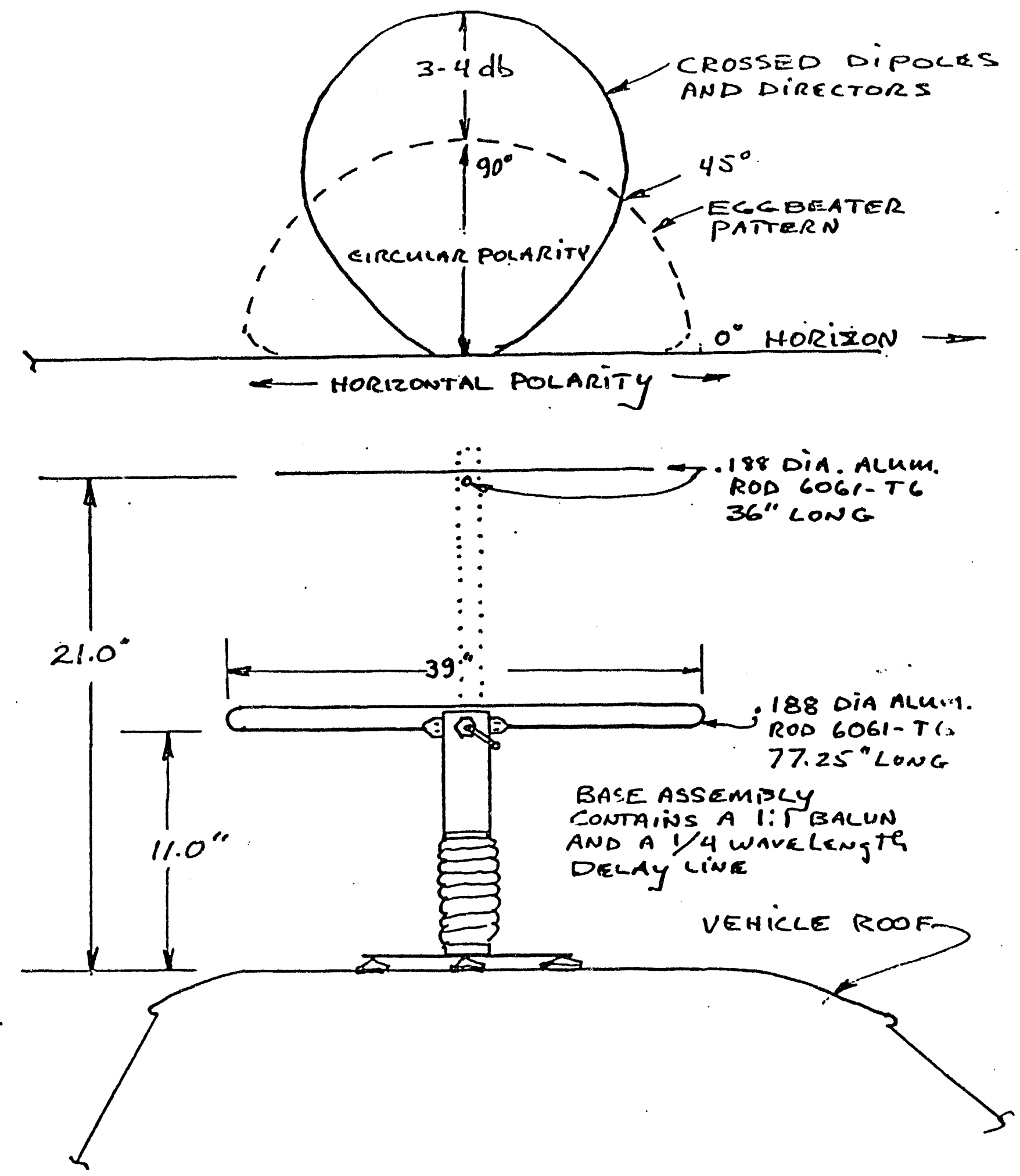

FIGURE 2. 
Dear Mr. Downey:

Enclosed is the Annual ATS-3 User's Report for 1986/1987. Again, I apologize for this report being ss late. I was picked for grand jury duty for the months of January, February, and March of this year. I have been working on this report part time folloving or $r$ telephone conversation on December 20, 1988.

The original draft of this report was much more comprehensive than what $I$ have included. My management considered much of the report too "electro-political" to be included. Our problem with releasing information from within Sandia National Laboratory (SNLA) stems from requirements levied upon us by the Department of Energy. I discussed this matter with you by telephone, so I know that you understand our situation.

Mr. Mel Pfeffer, President of VAL COMM. INC., is continuing to work with SNLA on this project and he and his personnel have been invaluable during these critical months of getting our new antenna station installed and the series of new tests implemented. Mr. Pfeffer has also been coordinating our test schedules and experiments with Mr. Paul Eden and personnel at your NASA LEWIS RESEARCH CENTER. W'e anticipate that the 1989/1990 Annual User's Report will cuntain more specific scientific data for your use. We are attempting to confine our test procedures to more methodical scientific testing and we will be furnishing you with data as it is being gathered. 
April 7, 1989

ATS-3 Satellite Usage

Thank you for your continued patience and cooperation in this effort. Please contact me if I can be of any further assistance.

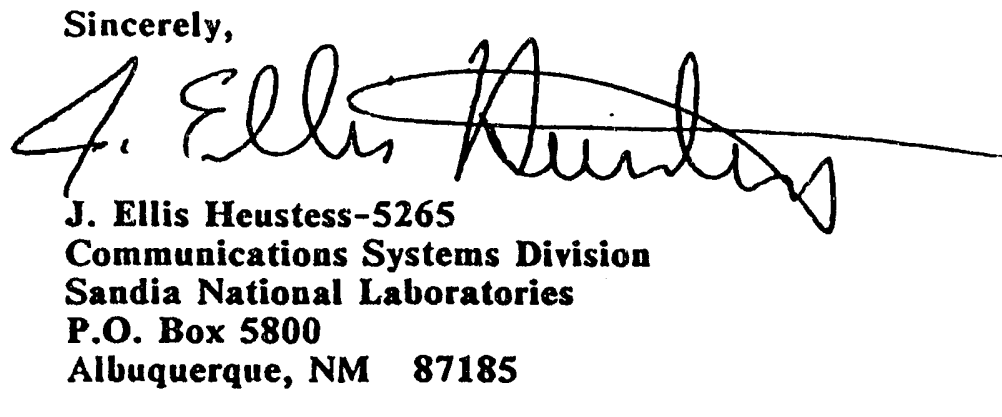

Phone: 505-844-4206, FTS: 844-4206

JEH:5265:jeh

Copy to:

5265 Larry G. Stotts

5265 Emmett L. Sandoval

5265 J. Ellis Heustess

5265 File

AL COMM, INC. Attn: Mel Pfeffer 


\section{SPECIFICATIONS}

Model number

$149-\mathrm{C} 22$

Frequency range

Gain

Beamwidth

Polarity

Front to back

Feed impedance

Connector

Power handling

Boom length

Boom diameter

Parasitic elements

wind area

Mast size

weight

Shipping weight

\author{
$149-\mathrm{C} 22$ \\ 144 to $150 \mathrm{mHz}$ \\ $12.1 \mathrm{dBdC}$ \\ 40 degrees \\ circular, RHC or LHC \\ 20 dB typical \\ 50 Ohms unbalanced \\ ' $N$ ' female \\ $1.5 \mathrm{KW}$ \\ $216^{\prime \prime}$ \\ $1-1 / 2 "$ tapering to $1 "$ \\ $20,3 / 16 "$ alum. rod \\ $2.5 \mathrm{sq}$. ft. \\ $1-1 / 2$ " to $2-1 / 8$ " \\ $12.51 \mathrm{bs}$ \\ 14 lbs, UPS
}

\section{FEATURES}

This crosspolarized Yagi is designed for the serious satellite user ie. OSCAR or ATS and is ideal for larger arrays where control station function is required. It features a sealed, weather tight driven element assembly and phasing network for minimal maintainence. The elements are centered in the boom for minimum interaction and good elipticity. 
Feb. 71989

ASSEMBLI! INSTRUCTIONS

REV. MAY 11, 1989

135-C22 AND 149-C22 ANTENNAS

TOOLS REQUIRED: Tape measure, $11 / 32 "$ socket, spin-tite or end wrench, flat blade screwdriver, 7/16" end wrench, needle nose pliers. and a $1 / 2 "$ socket or end wrench.

NOTE: This antenna is made up of two basically identical

Yagi type antennas, one set beginning at the extreme rear of the boom and the other set beginning one quarterwave in front and in a plane at right angles to the other antenna.

1. ASSEMBLING THE BOOM. Note the boom drawing and start with the rear one inch diameter section and the rear $1-1 / 4$ " section. Slip the one inch section into the swaged or necked down end of the rear 1-1/4" section, align the two screw holes and add two 8-32 x 1-1/2" screws, lockwashers and nuts and tighten.

Next, add the 1-1/2" section, again noting hole positions referenced to the end that connects to the rear $1-1 / 4 "$ section. Slip the two sections together and add the $8-32 \mathrm{x}$ $1-3 / 4 "$ screws, lockwashers and nuts and tighten.

Now add the front $1-1 / 4 "$ and $1 "$ diameter sections in similar manner. This completes the boom assembly.

NOTE: At this point it may be handy to add the $4 \times 6 " x$ $3 / 16 "$ boom to mast plate using two 1-1/2" U-bolts and cradles. Locate the plate TEMPORARILY at 104." from the rear of the boom and mount the plate in a vice or on a temporary mast to hold the antenna about waist high for easy element installation.

2. ELEMENT INSTALLATION. Begin at the rear of the boom. Locate a REFLECTOR (see drawing $x$ 3/16") rod element and slide on a black button insulator to the balance point or approximate middle. Insert the rod in through the rear set of 5/16" diameter holes and install the second button insulator, and push both insulators up tight against the boom. Center the element only approximately because it is easier to center all the elements in this plane at one time.

3. The next rod element to install is part of the driven element assembly. Refer to the ANTENNA DIMENSION DRAWING for the proper length. Install it the same as the reflector element. Continue installing 3/16" rod elements until all are in place.

4. CENTERING THE ELEMENTS. It is generally easiest to use a tape measure and simply equalize the amount of element sticking out of the boom on each side to within $1 / 16$ inch. once this is completed for all the elements, sight down the tips of the elements from the rear of the boom and look for 
ELEMENT SPACING
$\mathrm{H}$
$\mathrm{V}$

0.50

16.0

22.5

35.75

35.0

41.50

$52.625 \quad 54.625$

71.625

72.5

94.50

91.50

113.125

118.125

137.125

143.375

162.375

169.875

189.25

197.50

Mike Staal 5-11-89

216.50
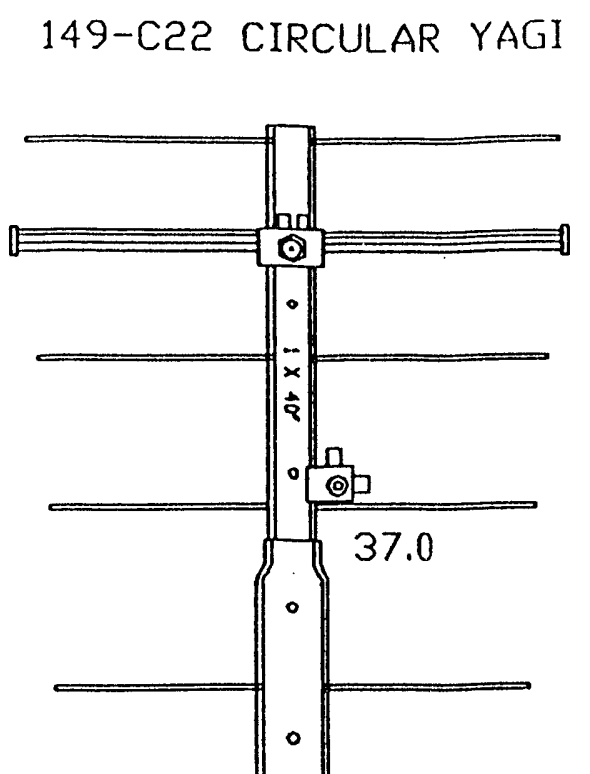

35.75

35.313

39.0

35.75

35.875

35.313

35.062

35.062

34.75

34.75

34.50

34.50

34.188

34.188

34.0

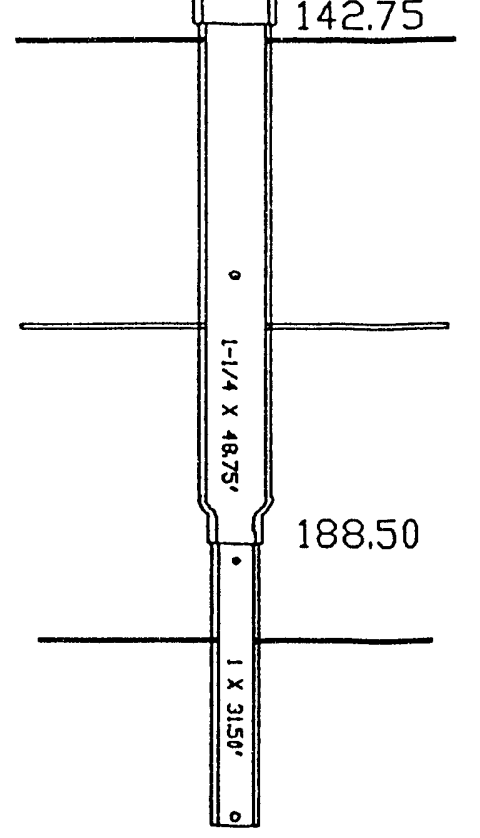

ENGT

38.50

39.0

35.875

82.75

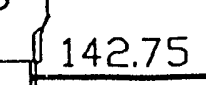


gross irregularities. Correct if found and prepare to install the element retainers or KEEPERS.

5. INSTALLING THE KEEPERS. Locate the $3^{\prime \prime} \times 3 / 8 "$ aluminum tube (INSERTION TOOL). Start a keeper on the end of the first element with your fingers. BE SURE TO HOIJ THE ELEMENT FIRMLY TO PREVENT IT FROM SLIDING OFF CENTER. Using the INSERTION TOOL, push the keeper up against the button insulator. Repeat for the other side. Continue until all the keepers are in place.

6. INSTALLING THE SECOND SET OF ELEMENTS. Again, refer to the ANTENNA DIMENSICIN DRAWING and install the second set of elements the same as the first set.

7. DRIVEN ELEMENT ASSEMBLY. Mount the DRIVEN ELEMENTS as shown in the sketch with the two BALUN connectors to the rear. NOTE the position of the blocks is critical and it is shown in the RIGHT HAND CIRCULAR position. If LEFT HAND CIRCULAR is required, reverse the side the front block is mounted on. Use 8-32 x 1-1/4" screws to attach the blocks to the boom and tighten in place. Add the JUNCTION BLOCK as shown, with the ' $N$ ' connector facing the rear, fastening with another 8-32 $\times 1-1 / 4 "$ screw.

Attach the SHORTING BLOCKS to the ends of the driven elements and tighten in place with the 5/64" allen wrench provided.

orient the boom so the REAR driven element block and the JUNCTION BLOCK is on the TOP of the boom. Now insert the U shaped 3/16" rod pieces into the boom from the top through the two sets of one inch holes spaced to accept the rod ends. Install KEEPERS on each rod end as it protrudes from the bottom of the boom. These $U$ clips form attach points for the black Dacron boom support cable installed near antenna completion.

8. ADDING THE BALUNS AND PHASING HARNESS. The BALUN cables are about 3 feet long and the PHASING CABLES are half as long. Attach the baluns first and tighten the connectors GENTLY with a 7/16" end wrench while holding the body of the connector with a pair of needle nose pliers. This prevents the cable from twisting during installation. DAMAGE OR LOSS OF WATER SEAL CAN OCCUR IF THE CABLE IS TWISTED. NOW add the phasing cables as shown in the sketch. Tighten the same as the balun connectors.

9. FINALIZING THE ANTENNA. The main feedline is attached now and routes back to the rear of the boom. USING THE BLACK CABLE TIES provided, form the various cables against the boom and AWAY FROM ELEMENTS. The last tie point for the main feedline should be just about one inch in front of the rear REFLECTOR. and coming away at right angles to it. 


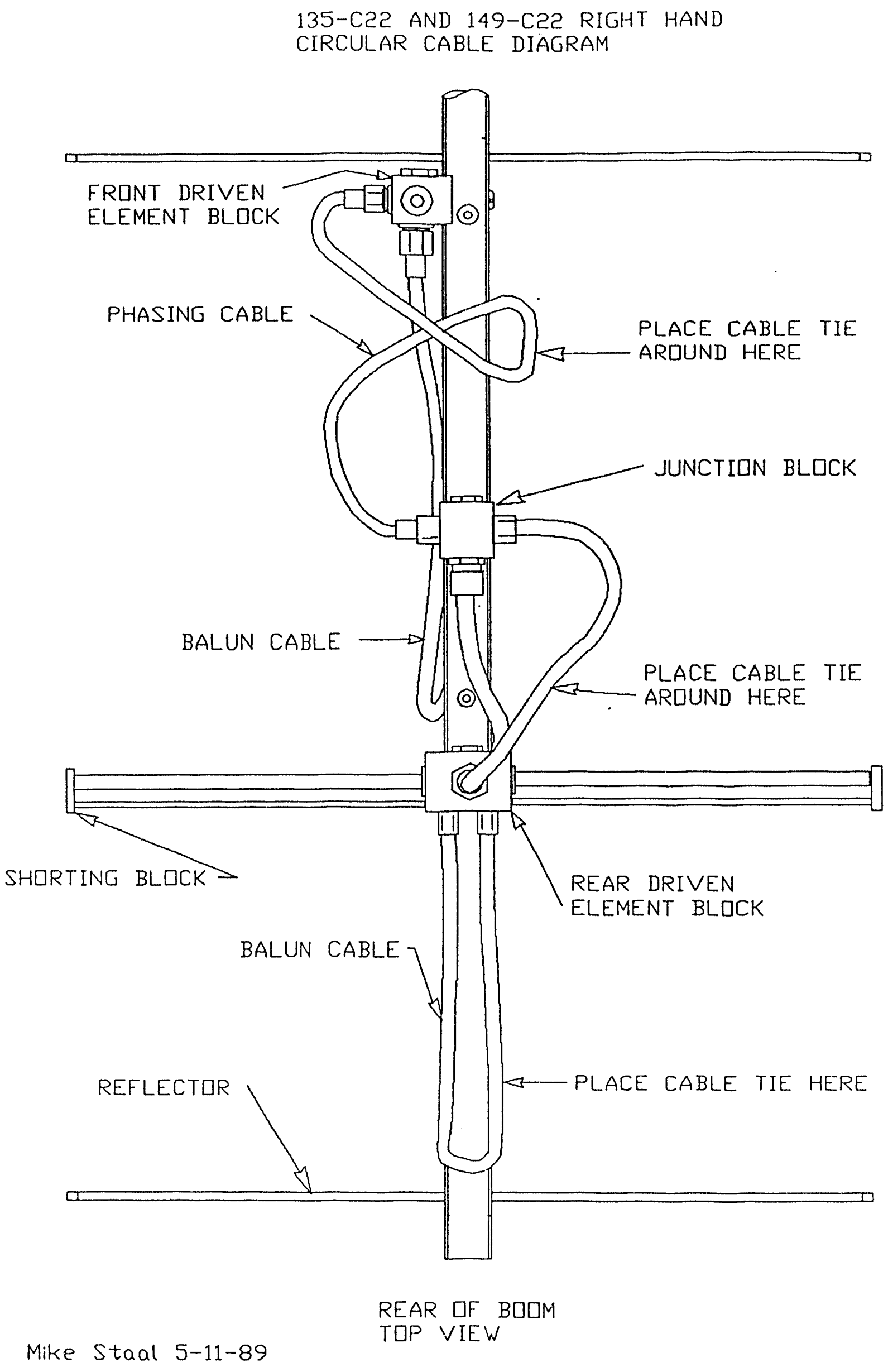


10. Position and tighten the BOOM TO MAST PLATE moderately at THE PHYSICAL BALANCE POINT of the boom and align it with the forward set of elements. THESE ELEMENTS WILL BE VERTICALLY POLARIZED WHEN THE ANTENNA IS MOUNTED ON THE SUPPORT MAST OR ' $H$ ' FRAME.

Install the last $2 " U$-bolt into the small TURNBUCKLE PLATE and attach the turn buckles. If possible install a short (one foot long or less) temporary mast section through the 2 inch U-bolts in the boom to mast plate and slide on the turnbuckle plate right down against the boom to mast plate ALTERNATELY, temporarily install the turnbuckle U-bolt into the top set of U-bolt holes in the boom to mast plate. This "locks" the alignment of the turnbuckle plate to the boom to mast position. Now attach one end of the BLACK DACRON SUPPORT LINE to the front U clip. Two turns of line and a square knot is adequate and tape the left over end back to the main line to prevent fraying. Route the line back to the forward turnbuckle which should be extended till both threaded ends just protrude into the body of the turnbuckle. cut the line about a foot past the turnbuckle and attach it to the turnbuckle as on the U clip. Repeat for the rear section of support line. When completed, the two lines should be tight, the turnbuckles laying flat out just over the boom and the turnbuckle plate U-bolt CENTERED over the two other U-bolts in the boom to mast plate. When the antenna is installed in a mast, the turnbuckle plate is slid up one foot above the boom and after turnbuckle adjustment, the boom should be perfectly straight.

THIS COMPLETES THE ANTENNA ASSEMBLY. THE RECOMMENDED MAST FOR THIS ANTENNA IS TWO INCH DIAMETER 1/4" WALL FIBERGLASS OR EQUIVALENT. DO NOT MOUNT ON A METAL MAST OR RUN THE MAIN FEEDLINE FORWARD AND DOWN THE MAST AS THE ANTENNAS VSWR, GAIN AND CIRCULARITY WILL BE DEGRADED.

CAREFULLY MANUFACTURED BY:

M2 ENTERPRISES

7560 N. DEL MAR AV.

FRESNO, CA. 93711

209-432-8873 FAX $209432-3059$ 
149-C22 ANTENNA

PART LIST

Boom section $1 " x .058 \times 40.0$ aluminum 1

Boom section $1^{\prime} x .058 \times 31.5$ aluminum 1

Boom section $1-1 / 4 " x .058 \times 48.75$ aluminum 1

Boom section $1-1 / 4 " x .058 \times 48.75$ aluminum 1

Boom section $1-1 / 2 " \times .058 \times 60.0$ aluminum 1

Driven element assembly top section 2

Driven element rod $3 / 16 \times \quad 2$

Parasitic elements rod (see drawing for lengths 20

Balun cable RG-6U with sealed ' $F$ ' fittings 2

Phasing cables RG-6 with sealed 'F'fittings 2

Junction block machined aluminum 1

Boom to mast plate $4 \times 63 / 16 " 1$

Turnbuckle plate $1-1 / 2 \times 4 " 1$

Dacron support line $3 / 32 \times 1$

U-bolt 2" 3

U-bolt 1-1/2"

Assembly instructions 1

HARDWARE BAG

Turnbuckles 1/4" 2

Nuts 5/16-18 stainless (for U-bolts) 10

lockwashers 5/16" split ring stainless 10

Shorting blocks machined aluminum 4

Screw $8-32 \times 1-3 / 4$ slot panhead stainless 4

Screw 8-32 x 1-1/2" slot panhead stainless 4

Screw 8-32 x 1-1/4" slot panhead stainless 3

Nuts $8-32$ ss 8

Lockwashers \#8 8

set screw 8-32 x 3/16" int. hex stainless 8

Allen wrench 5/64" 1

$\mathrm{U}$ clips $3 / 16$ rod formed 2

Button insulator black 3/16" 44

Keeper stainless $3 / 16 " 18$

Insertion tool $3 \times 3 / 8 "$ aluminum 1

Nylon ties black 5 
SPECIFICATIONS

Model number

$149-\mathrm{C} 22$

Frequency range

$149-\mathrm{C} 22$

144 to $150 \mathrm{mHz}$

Gain

Beamwidth

Polarity

Front to back

Feed impedance

Connector

Power handling

Boom length

Boom diameter

parasitic elements

wind area

Mast size

weight

Shipping weight

$12.1 \mathrm{dBdC}$

40 degrees

Circular, RHC or LHC

20 dB typical

50 Ohms unbalanced

' $N$ ' female

$1.5 \mathrm{KW}$

$216^{\prime \prime}$

$1-1 / 2$ " tapering to 1 "

$20,3 / 16^{\prime \prime}$ alum. rod

$2.5 \mathrm{sq}$. ft.

$1-1 / 2 "$ to $2-1 / 8$ "

$12.5 \mathrm{Ibs}$

14 lbs, UPS

\section{FEATURES}

This crosspolarized Yagi is designed for the serious satellite user ie. OSCAR or ATS and is ideal for larger arrays where control station function is required. It features a sealed, weather tight driven element assembly and phasing network for minimal maintainence. The elements are centered in the boom for minimum interaction and good elipticity. 


\section{ASSEMBLY INSTRUCTIONS \\ 135-C22 AND 149-C22 ANTENNAS}

Feb. 71989

REV. MAY 11, 1989

TOOLS REQUIRED: Tape measure, 11/32" socket, spin-tite or end wrench, flat blade screwdriver, 7/16" end wrench, needle nose pliers. and a $1 / 2$ " socket or end wrench.

NOTE: This antenna is made up of two basically identical Yagi type antennas, one set beginning at the extreme rear of the boom and the other set beginning one quarterwave in front and in a plane at right angles to the other antenna.

1. ASSEMBLING THE BOOM. Note the boom drawing and start with the rear one inch diameter section and the rear 1-1/4" section. slip the one inch section into the swaged or necked down end of the rear 1-1/4" section, align the two screw holes and add two 8-32 × 1-1/2" screws, lockwashers and nuts and tighten.

Next, add the 1-1/2" section, again noting hole positions referenced to the end that connects to the rear 1-1/4" section. Slip the two sections together and add the $8-32 \times$ 1-3/4" screws, lockwashers and nuts and tighten.

Now add the front $1-1 / 4 "$ and $1 "$ diameter sections in similar manner. This completes the boom assembly.

NOTE: At this point it may be handy to add the $4 \times 6 " \mathrm{x}$ $3 / 16 "$ boom to mast plate using two 1-1/2" U-bolts and cradles. Locate the plate TEMPORARILY at 104." from the rear of the boom and mount the plate in a vice or on a temporary mast to hold the antenna about waist high for easy element installation.

2. ELEMENT INSTALLATION. Begin at the rear of the boom. Locate a REFLECTOR (see drawing $x$ 3/16") rod element and slide on a black button insulator to the balance point or approximate middle. Insert the rod in through the rear set of 5/16" diameter holes and install the second button insulator, and push both insulators up tight against the boom. Center the element only approximately because it is easier to center all the elements in this plane at one time.

3. The next rod element to install is part of the driven element assembly. Refer to the ANTENNA DIMENSION DRAWING for the proper length. Install it the same as the reflector element. Continue installing $3 / 16 "$ rod elements until all are in place.

4. CENTERING THE ELEMENTS. It is generally easiest to use a tape measure and simply equalize the amount of element sticking out of the boom on each side to within $1 / 16$ inch. once this is completed for all the elements, sight down the tips of the elements from the rear of the boom and look for 


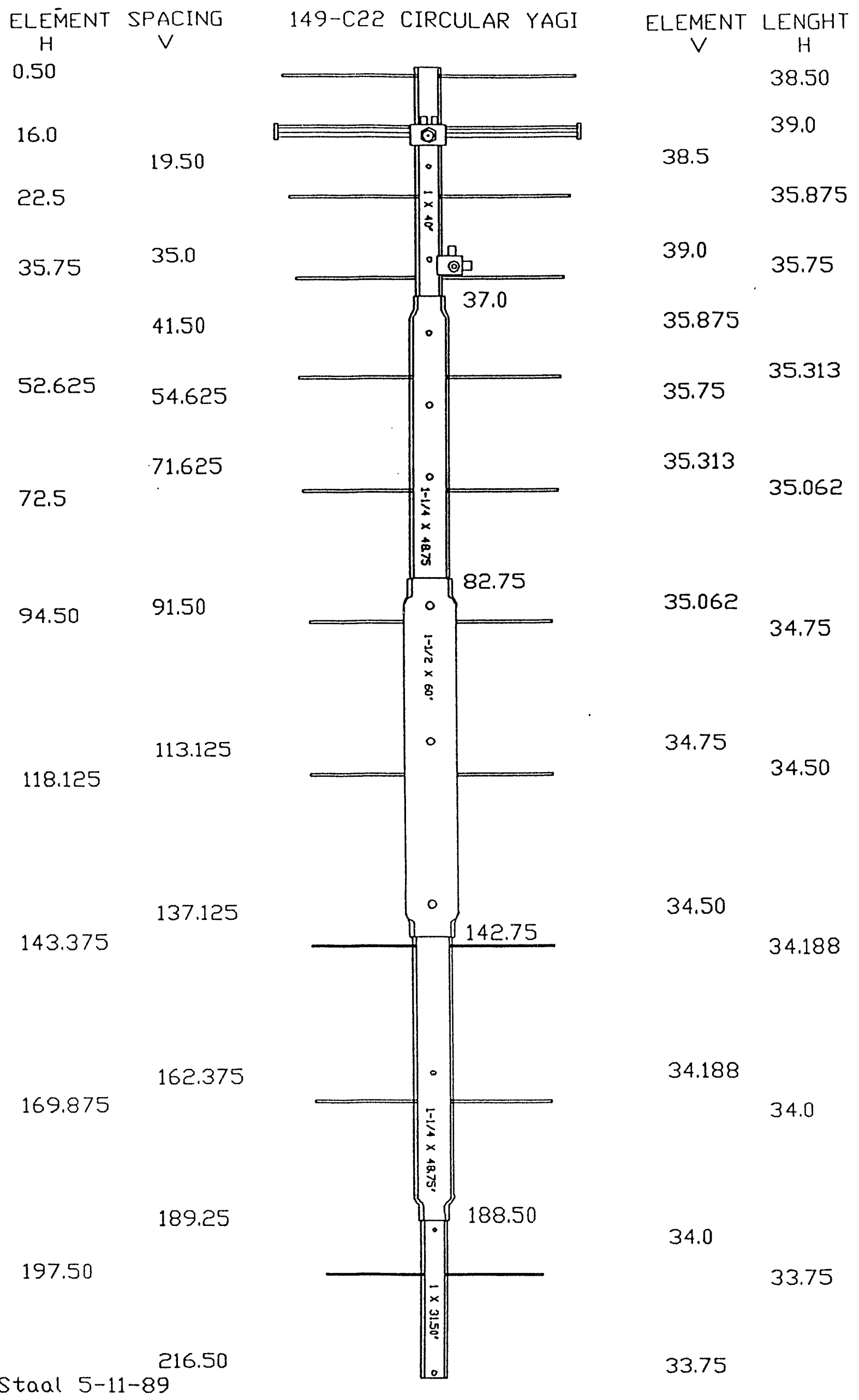


gross irregularities. Correct if found and prepare to install the element retainers or KEEPERS.

5. INSTALLING THE KEEPERS. Locate the 3" $\times 3 / 8 "$ aluminum tube (INSERTION TOOL). Start a keeper on the end of the first element with your fingers. BE SURE TO HOLD THE ELEMENT FIRMLY TO PREVENT IT FROM SLIDING OFF CENTER. Using the INSERTION TOOL, push the keeper up against the button insulator. Repeat for the other side. Continue until all the keepers are in place.

6. INSTALLING THE SECOND SET OF ELEMENTS. Again, refer to the ANTENNA DIMENSION DRAWING and install the second set of elements the same as the first set.

7. DRIVEN ELEMENT ASSEMBLY. Mount the DRIVEN ELEMENTS as shown in the sketch with the two BALUN connectors to the rear. NOTE the position of the blocks is critical and it is shown in the RIGHT HAND CIRCULAR position. If LEFT HAND CIRCULAR is required, reverse the side the front block is mounted on. Use 8-32 8 1-1/4" screws to attach the blocks to the boom and tighten in place. Add the JUNCTION BIOCK as shown, with the ' $N$ ' connector facing the rear, fastening with another 8-32 x 1-1/4" screw.

Attach the SHORTING BLOCKS to the ends of the driven elements and tighten in place with the 5/64" allen wrench provided.

Orient the boom so the REAR driven element block and the JUNCTION BLOCK is on the TOP of the boom. Now insert the $U$ shaped 3/16" rod pieces into the boom from the top through the two sets of one inch holes spaced to accept the rod ends. Install KEEPERS on each rod end as it protrudes from the bottom of the boom. These U clips form attach points for the black Dacron boom support cable installed near antenna completion.

8. ADDING THE BALUNS AND PHASING HARNESS. The BALUN cables are about 3 feet long and the PHASING CABLES are half as long. Attach the baluns first and tighten the connectors GENTLY with a 7/16" end wrench while holding the body of the connector with a pair of needle nose pliers. This prevents the cable from twisting during installation. DAMAGE OR LOSS OF WATER SEAL CAN OCCUR IF THE CABLE IS TWISTED. NOW add the phasing cables as shown in the sketch. Tighten the same as the balun connectors.

9. FINALIZING THE ANTENNA. The main feedline is attached now and routes back to the rear of the boom. USING THE BLACK CABLE TIES provided, form the various cables against the boom and AWAY FROM ELEMENTS. The last tie point for the main feedline should be just about one inch in front of the rear REFLECTOR. and coming away at right angles to it. 
135-C22 AND 149-C22 RIGHT HAND

CIRCULAR CABLE DIAGRAM

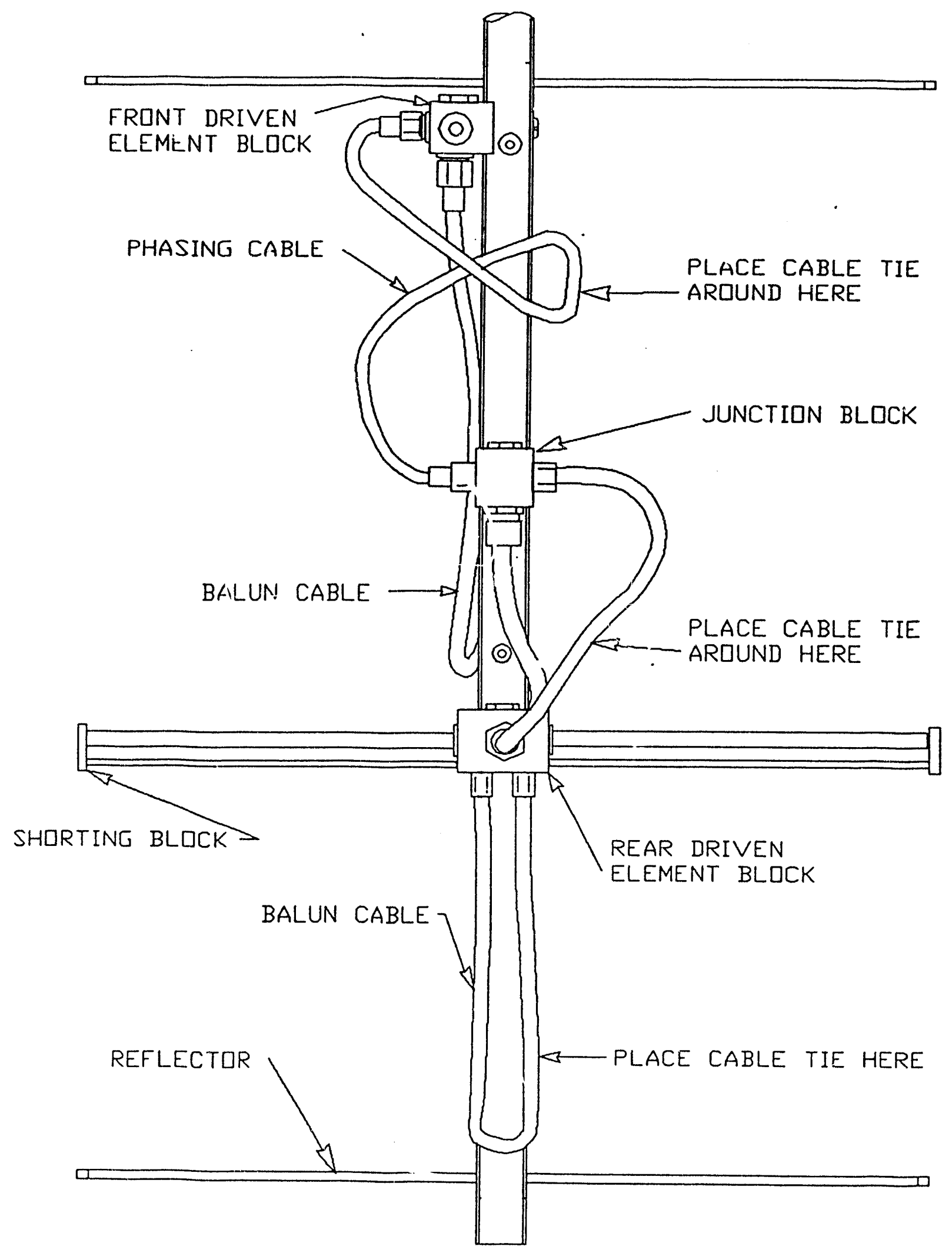

REAR DF BDOM

Mike Staal 5-11-89

TOP VIEW 
10. Position and tighten the BOOM TO MAST PLATE moderately at THE PHYSICAL BALANCE POINT of the boom and align it with the forward set of elements. THESE ELEMENTS WILL BE VERTICALLY POLARIZED WHEN THE ANTENNA IS MOUNTED ON THE SUPPORT MAST OR ' $H$ ' FRAME.

Install the last 2" U-bolt into the small TURNBUCKLE PLATE and attach the turn buckles. If possible install a short (one foot long or less) temporary mast section through the 2 inch U-bolts in the boom to mast plate and slide on the turnbuckle plate right down against the boom to mast plate ALTERNATELY, temporarily install the turnbuckle U-bolt into the top set of U-bolt holes in the boom to mast plate. This "locks" the alignment of the turnbuckle plate to the boom to mast position. Now attach one end of the BLACK DACRON SUPPORT LINE to the front U clip. Two turns of line and a square knot is adequate and tape the left over end back to the main line to prevent fraying. Route the line back to the forward turnbuckle which should be extended till both threaded ends just protrude into the body of the turnbuckle. cut the line about a foot past the turnbuckle and attach it to the turnbuckle as on the U clip. Repeat for the rear section of support line. When completed, the two lines should be tight, the turnbuckles laying flat out just over the boom and the turnbuckle plate U-bolt CENTERED over the two other U-bolts in the boom to mast plate. When the antenna is installed in a mast, the turnbuckle plate is slid up one foot above the boom and after turnbuckle adjustment, the boom should be perfectly straight.

THIS COMPLETES THE ANTENNA ASSEMBLY. THE RECOMMENDED MAST FOR THIS ANTENNA IS TWO INCH DIAMETER 1/4" WALL FIBERGLASS OR EQUIVALENT. DO NOT MOUNT ON A METAL MAST OR RUN THE MAIN FEEDLINE FORWARD AND DOWN THE MAST AS THE ANTENNAS VSWR, GAIN AND CIRCULARITY WILL BE DEGRADED.

CAREFULLY MANUFACTURED BY:

M2 ENTERPRISES

$7560 \mathrm{~N}$. DEL MAR AV.

FRESNO, CA. 93711

209-432-8873 FAX $209 \quad 432-3059$ 
149-C22 ANTENNA

PART LIST

Boom section $1 " x .058 \times 40.0$ aluminum 1

Boom section $1^{\prime} \times .058 \times 31.5$ aluminum 1

Boom section $1-1 / 4 " x .058 \times 48.75$ aluminum 1

Boom section $1-1 / 4 " x .058 \varkappa 48.75$ aluminum 1

Boom section $1-1 / 2 " x .058 \times 60.0$ aluminum 1

Driven element assembly top section 2

Driven element rod $3 / 16 \times 2$

Parasitic elements rod (see drawing for lengths 20

Balun cable RG-6U with sealed 'F' fittings 2

Phasing cables RG-6 with sealed 'F'fittings 2

Junction block machined aluminum 1

Boom to mast plate $4 \times 63 / 16^{\prime \prime} 1$

Turnbuckle plate $1-1 / 2 \times 4 " 1$

Dacron support line $3 / 32 \times 1$

U-bolt 2 "

U-bolt $1-1 / 2 "$

Assembly instructions 2

HARDWARE BAG

Turnbuckles $1 / 4 "$

Nuts 5/16-18 stainless (for U-bolts) 10

lockwashers 5/16" split ring stainless 10

Shorting blocks machined aluminum 4

Screw 8-32 $81-3 / 4$ slot panhead stainless 4

Screw 8-32 x 1-1/2" slot panhead stainless 4

Screw 8-32 x 1-1/4" slot panhead stainless 3

Nuts $8-32$ ss 8

Lockwashers \#8 8

Set screw 8-32 × 3/16" int. hex stainless 8

Allen wrench 5/64" 1

$\mathrm{U}$ clips $3 / 16$ rod formed 2

Button insulator black 3/16" 44

Keeper stainless $3 / 16 " 148$

Insertion tool $3 \times 3 / 8 "$ aluminum 1

Nylon ties black 5 
SPECIFICATIONS

MODEL 135-C22 CIRCULAR POLARIZED YAGI

Model number

Frequency range

Gain

Beamwidth

Polarity

Front to back

Feed impedance

Connector

Power handling

Boom length

Boom diameter

Parasitic elements

wind area

Mast size

weight

Shipping weight
135-C22

135 to $137 \mathrm{mHz}$

$12.1 \mathrm{dBdC}$

40 degrees

Circular, RHC or LHC

20 dB typical

50 Ohms unbalanced

' $N$ ' female

$1.5 \mathrm{KW}$

$237^{\prime \prime}$

$1-1 / 2$ "tapering to $1 "$

$20,3 / 16^{\prime \prime}$ alum. rod

$2.75 \mathrm{sq}$. ft.

$1-1 / 2$ " to $2-1 / 8$ "

13 lbs

14 lbs, UPS

\section{FEATURES}

This crosspolarized Yagi is designed for the serious satellite user ie. OSCAR or ATS and is ideal for larger arrays where control station function is required. It features a sealed, weather tight driven element assembly and phasing network for minimal maintainence. The elements are centered in the boom for minimum interaction and good elipticity. 


\section{ASSEMBLY INSTRUCTIONS 135-C22 ANTENNA}

TOOLS REQUIRED: Tape measure, 11/3;" socket,spin-tite or end wrench, flat blade screwdriver, 7/16" end wrench, needle nose pliers. and a $1 / 2$ " socket or end wrench.

NOTE: This antenna is made up of two basically identical Yagi type antennas, one set beginning at the extreme rear of the boom and the other set beginning one quarterwave in front and in a plane at right angles to the other antenna.

1. ASSEMBLING THE BOOM. Note the boom drawing and start with the rear one inch diameter section and the rear 1-1/4" section. Slip the one inch section into the swaged or necked down end of the rear 1-1/4" section, align the two screw holes and add two 8-32 x 1-1/2" screws, lockwashers and nuts and tighten.

Next, add the 1-1/2" section, again noting hole positions referenced to the end that connects to the rear $1-1 / 4 "$ section. Slip the two sections together and add the $8-32 \times$ 1-3/4" screws, lockwashers and nuts and tighten.

Now add the front $1-1 / 4 "$ and $1 "$ diameter sections in similar manner. This completes the boom assembly.

NOTE: At this point it may be handy to add the $4 \times 6^{\prime \prime} x$ $3 / 16 "$ boom to mast plate using two $1-1 / 2 " U$-bolts and cradles. Locate the plate at 104" from the rear of the boom and mount the plate in a vice or on a temporary mast to hold the antenna about waist high for easy element installation.

2. ELEMENT INSTALLATION. Begin at the rear of the boom. Locate a REFLECTOR (see drawing $\times 3 / 16 "$ ) rod element and slide on a black button insulator to the balance point or approximate middle. Insert the rod in through the rear set of 5/16" diameter holes and install the second button insulator, and pusn both insulators up tight against the boom. Center the element only approximately because it is easier to center all the elements in this plane at one time.

3. The next rod element to install is part of the driven element assembly. Refer to the ANTENNA DIMENSION DRAWING for the proper length. Install it the same as the reflector element. Continue installing $3 / 16 "$ rod elements until all are in place.

4. CENTERING THE ELEMENTS. It is generally easiest to use a tape measure and simply equalize the amount of element sticking out of the boom on each side to within $1 / 16$ inch. Once this is completed for all the elements, sight down the tips of the elements from the rear of the boom and look for gross irregularities. Correct if found and prepare to install the element retainers or KEEPERS. 
ELEMENT SPACING

$\mathrm{H} \quad \mathrm{V}$

0.5

17.5

24.562

39.0

38.25

45.562

57.625

60.0

79.375

78.625

100.375

103.437

124.437

129.5

150.5

157.125

178.125

186.125

207.125

216.437
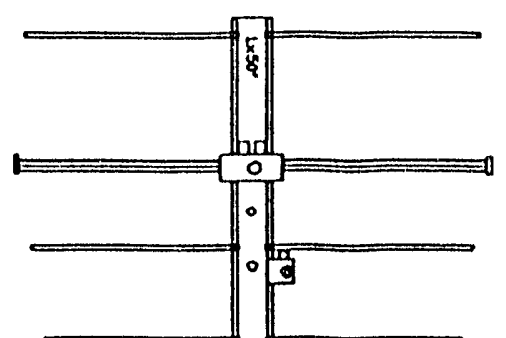

47.0
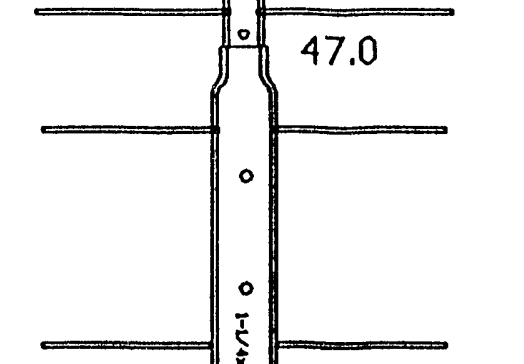

38.75

38.375

38.437

38.125

38.125

37.813

37.875

37.562

154.0

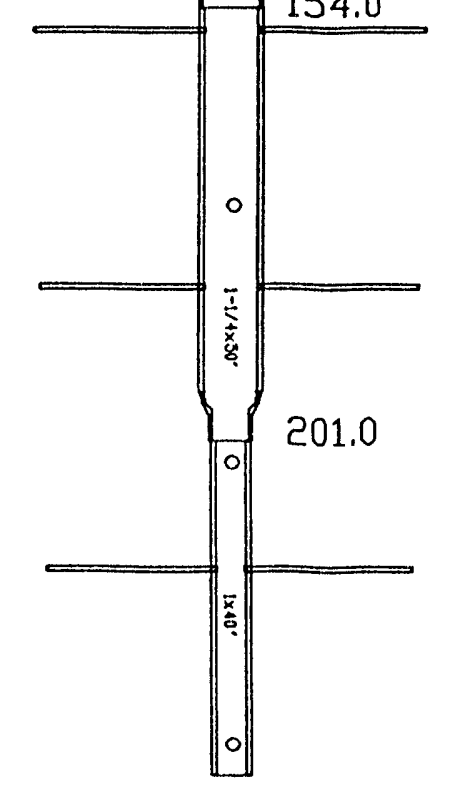

42.0

42.5

39.375

39.062

38.75

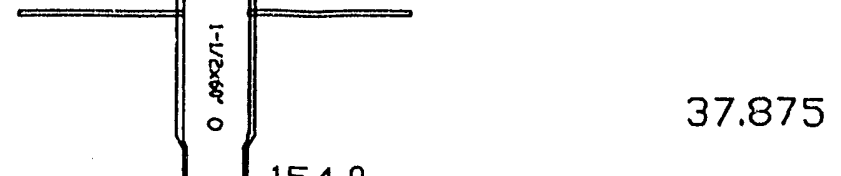

37.562

37.562

37.25

37.313

37.062

37.062

135-C22 CIRCULAR POLARIZED YAG: Mike Staal 5-10-89 
5. INSTALLING THE KEEPERS. Locate the $3 " x 3 / 8$ " aluminum tube (INSERTION TOOL). Start a keeper on the end of the first element with your fingers. BE SURE TO HOLD THE ELEMENT FIRMLY TO PREVENT IT FROM SLIDING OFF CENTER. Using the INSERTION TOOL, push the keeper up against the button insulator. Repeat for the other side. Continue until all the keepers are in place.

6. INSTALLING THE SECOND SET OF ELEMENTS. Again, refer to the ANTENNA DIMENSION DRAWING and install the second set of elements the same as the first set.

7. DRIVEN ELEMENT ASSEMBLY. Mount the DRIVEN ELEMENTS as shown in the sketch with the two BAIUN connectors to the rear. NOTE the position of the blocks is critical and it is shown in the RIGHT HAND CIRCULAR position. If LEFT HAND CIRCULAR is required, reverse the side the front block is mounted on. Use 8-32 $\times 1-1 / 4 "$ screws to attach the blocks to the boom and tighten in place. Add the JUNCTION BLOCK as shown, with the ' $N$ ' connector facing the rear, fastening with another 8-32 x 1-1/4" screw.

Attach the SHORTING BLOCKS to the ends of the driven elements and tighten in place with the 5/64" allen wrench provided.

orient the boom so the REAR driven element block and the JUNCTION BLOCK is on the TOP of the boom. NOW insert the $U$ shaped 3/16" rod pieces into the boom from the top through the two sets of one inch holes spaced to accept the rod ends. Install KEEPERS on each rod end as it protrudes from the bottom of the boom. These U clips form attach points for the black Dacron boom support cable installed near antenna completion.

8. ADDING THE BALUNS AND PHASING HARNESS. The BALUN cables are about 3 feet long and the PHASING CABLES are half as long. Attach the baluns first and tighten the connectors GENTLY with a 7/16" end wrench while holding the body of the connector with a pair of needle nose pliers. This prevents the cable from twisting during installation. Now add the phasing cables as shown in the sketch. Tighten the same as the balun connectors.

9. FINALIZING THE ANTENNA. The main feedline is attached now and routes back to the rear of the boom. USING THE BLACK CABLE TIES provided, form the various cables against the boom and AWAY FROM ELEMENTS. The last tie point for the main feedline should be just about one inch in front of the rear REFLECTOR, and coming away at right angles to it.

10. Position and tighten the BOOM TO MAST PLATE moderately at inches from the rear of the boom and align it with 
135-C22 AND 149-C22 RIGHT HAND

CIRCULAR CABLE DIAGRAM

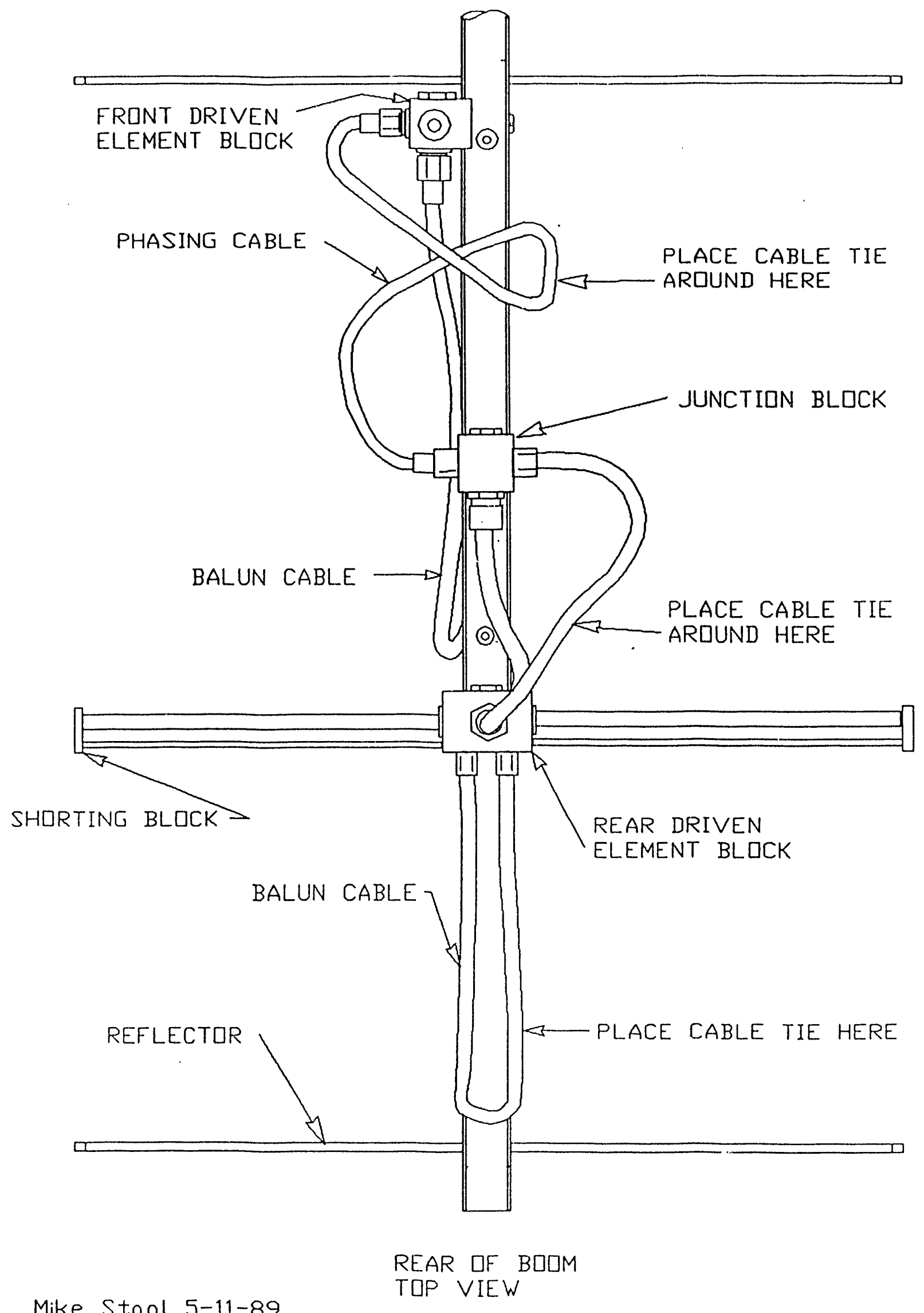


10. Position and tighten the BOOM TO MAST PLATE moderately at inches from the rear of the boom and align it with the forward set of elements. THESE ELEMENTS WILL BE VERTICALLY POLARIZED WHEN THE ANTENNA IS MOUNTED ON THE SUPPORT MAST OR ' $H$ ' FRAME.

Install the last 2" U-bolt into the small TURNBUCKLE PLATE and attach the turn buckles. If possible install a short (one foot long or less) temporary mast section through the 2 inch U-bolts in the boom to mast plate and slide on the turnbuckle plate right down against the boom to mast plate ALTERNATELY, temporarily install the turnbuckle U-bolt into the top set of U-bolt holes in the boom to mast plate. This "locks" the alignment of the turnbuckle plate to the boom to mast position. Now attach one end of the BLACK DACRON SUPPORT LINE to the front $U$ clip. Two turns of line and a square knot is adequate and tape the left over end back to the main line to prevent fraying. Route the line back to the forward turnbuckle which should be extended till both threaded ends just protrude into the body of the turnbuckle. cut the line about a foot past the turnbuckle and attach it to the turnbuckle as on the U clip. Repeat for the rear section of support line. When completed, the two lines should be tight, the turnbuckles laying flat out just over the boom and the turnbuckle plate U-bolt CENTERED over the two other U-bolts in the boom to mast plate. When the antenna is installed in a mast, the turnbuckle plate is slid up one foot above the boom and after turnbuckle adjustment, the boom should be perfectly straight.

THIS COMPLETES THE ANTENNA ASSEMBLY. THE RECOMMENDED MAST FOR THIS ANTENNA IS TWO INCH DIAMETER 1/4" WALL FIBERGLASS OR EQUIVALENT. DO NOT MOUNT ON A METAL MAST OR RUN THE MAIN FEEDLINE FORWARD AND DOWN THE MAST AS THE ANTENNAS VSWR, GAIN AND CIRCULARITY WILL BE DEGRADED.

CAREFULLY MANUFACTURED BY :

M2 ENTERPRISES

7560 N. DEL MAR AV.

FRESNO CA. 93711

209-432-8873 FAX $209 \quad 432-3059$ 


\section{5-C22 ANTENNA}

\section{PART LIST}

Boom section $1^{\prime \prime} \times .058 \times 50.0$ aluminum 1

Boom section $1^{\prime} \times .058 \times 40.0$ aluminum 1

Boom section $1-1 / 4 " \times .058 \times 50.0$ aluminum 1

Boom section $1-1 / 4 " x .058 \times 50.0$ aluminum 1

Boom section $1-1 / 2 " \times .058 \times 60.0$ aluminum 1

Driven element assembly top section 2

Driven element rod $3 / 16 \mathrm{x} 2$

Parasitic elements rod (see drawing for lengths 20

Balun cable RG-6U with sealed ' $F$ ' fittings 2

Phasing cables $R G-6$ with sealed 'F'fittings 2

Junction block machined aluminum 1

Boom to mast plate $4 \times 63 / 16 " 1$

Turnbuckle plate $1-1 / 2 \times 4 " 1$

Dacron support line $3 / 32 \times 1$

U-bolt 2" 3

U-bolt $1-1 / 2 "$

Assembly instructions 1

HARDWARE BAG

Turnbuckles $1 / 4^{\prime \prime} \quad 2$

Nuts 5/16-18 stainless (for U-bolts) 10

lockwashers 5/16" split ring stainless 10

Shorting blocks machined aluminum 4

Screw 8-32 × 1-3/4 slot panhead stainless 4

Screw 8-32 $\times 1-1 / 2 "$ slot panhead stainless 4

Screw 8-32 x 1-1/4" slot panhead stainless 3

set screw 8-32 x 3/16" int. hex stainless 8

Nut 8-32 hex stainless . 8

Lockwasher \#8 split ring stainless 8

Allen wrench 5/64" 1

$U$ clips $3 / 16$ rod formed 2

Button insulator black 3/16" 44

Keeper stainless 3/16" 48

Insertion tool $3 \times 3 / 8 "$ aluminum 1

Nylon ties black 5 
Model number

Frequency range

Gain

Beamwidth

Polarity

Front to back

Feed impedance

Connector

Power handling

Boom length

Boom diameter

Parasitic elements

wind area

Mast size

weight

Shipping weight
$135-\mathrm{C} 22$

135 to $137 \mathrm{mHz}$

$12.1 \mathrm{dBdc}$

40 degrees

Circular, RHC or LHC

20 dB typical

50 Ohms unbalanced

' $N$ ' female

$1.5 \mathrm{KW}$

2371

$1-1 / 2$ " tapering to 1 "

$20,3 / 16^{\prime \prime}$ alum. rod

$2.75 \mathrm{sq}$. ft.

$1-1 / 2$ " to $2-1 . / 8$ "

13 lbs

14 lbs, UPS

\section{FEATURES}

This crosspolarized Yagi is designed for the serious satellite user ie. OSCAR or ATS and is ideal for larger arrays where control station function is required. It features a sealed, weather tight driven element assembly and phasing network for minimal maintainence. The elements are centered in the boom for minimum interaction and good elipticity. 


\section{Feb. 71989 \\ ASSEMBLY INSTRUCTIONS 135-C22 ANTENNA}

TOOLS REQUIRED: Tape measure, 11/32" socket, spin-tite or end wrench, flat blade screwdriver, 7/16" end wrench, needle nose pliers. and a $1 / 2$ " socket or end wrench.

NOTE: This antenna is made up of two basically identical Yagi type antennas, one set beginning at the extreme rear of the boom and the other set beginning one quarterwave in front and in a plane at right angles to the other antenna.

1. ASSEMBLING THE BOOM. Note the boom drawing and start with the rear one inch diameter section and the rear $1-1 / 4$ " section. Slip the one inch section into the swaged or necked down end of the rear 1-1/4" section, align the two screw holes and add two 8-32 x 1-1/2" screws, lockwashers and nuts and tighten.

Next, add the 1-1/2" section, again noting hole positions referenced to the end that connects to the rear $1-1 / 4 "$ section. Slip the two sections together and add the $8-32 \times$ $1-3 / 4 "$ screws, lockwashers and nuts and tighten.

Now add the front 1-1/4" and 1" diameter sections in similar manner. This completes the boom assembly.

NOTE: At this point it may be handy to add the $4 \times 6$ " $x$ $3 / 16 "$ boom to mast plate using two 1-1/2" U-bolts and cradles. Locate the plate at 104 " from the rear of the boom and mount the plate in a vice or on a temporary mast to hold the antenna about waist high for easy element installation.

2. ELEMENT INSTALLATION. Begin at the rear of the boom. Locate a REFLECTOR (see drawing $x$ 3/16") rod element and slide on a black button insulator to the balance point or approximate middle. Insert the rod in through the rear set of 5/16" diameter holes and install the second button insulator, and push both insulators up tight against the boom. Center the element only approximately because it is easier to center all the elements in this plane at one time.

3. The next rod element to install is part of the driven element assembly. Refer to the ANTENNA DIMENSION DRAWING for the proper length. Install it the same as the reflector element. Continue installing $3 / 16^{\prime \prime}$ rod elements until all are in place.

4. CENTERING THE ELEMENTS. It is generally easiest to use a tape measure and simply equalize the amount of element sticking out of the boom on each side to within $1 / 16$ inch. once this is completed for all the elements, sight down the tips of the elements from the rear of the boom and look for gross irregularities. Correct if found and prepare to install the element retainers or KEEPERS. 
ELEMENT SPACING

$H \quad V$

0.5

17.5

24.562

39.0

57.625

57.625

$79.375 \quad 78.625$

100.375

103.437

124.437

129.5

150.5

$157.125 \ldots$

178.125

186.125

207.125

216.437

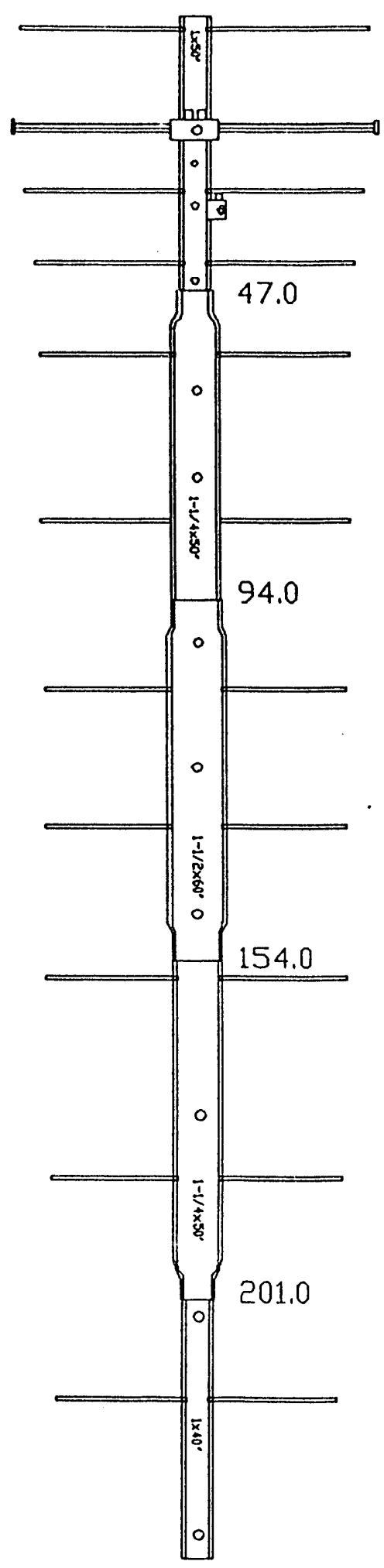

ELEMENT LENGTH

$\checkmark \quad H$

42.0

42.5

42.0

42.5

39.375

39.062

39.375

38.75

39.125

38.75

38.375

38.437

38.125

38.125

37.813

37.875

37.562

37.562

37.25

37.313

37.062

37.062

135-C22 CIRCULAR PILARIZED YAG: Mike Staal 5-10-89 
5. INSTALLING THE KEEPERS. Locate the $3 " \times 3 / 8 "$ aluminum tube (INSERTION TOOL). Start a keeper on the end of the first element with your fingers. BE SURE TO HOLD THE ELEMENT FIRMLY TO PREVENT IT FROM SLIDING OFF CENTER. Using the INSERTION TOOL, push the keeper up against the button insulator. Repeat for the other side. Continue until all the keepers are in place.

6. INSTALLING THE SECOND SET OF ELEMENTS. Again, refer to the ANTENNA DIMENSION DRAWING and install the second set of elements the same as the first set.

7. DRIVEN ELEMENT ASSEMBLY. Mount the DRIVEN ELEMENTS as shown in the sketch with the two BALUN connectors to the rear. NOTE the position of the blocks is critical and it is showr: in the RIGHT HAND CIRCULAR position. If LEFT HAND CIRCULAR is required, reverse the side the front block is mounted on. Use 8-32 8 1-1/4" screws to attach the blocks to the boom and tighten in place. Add the JUNCTION BLOCK as shoivn, with the ' $N$ ' connector facing the rear, fastening with another 8-32 x 1-1/4" screw.

Attach the SHORTING BLOCKS to the ends of the driven elements and tighten in place with the 5/64" allen wrench provided.

Orient the boom so the REAR driven element block and the JUNCTION BLOCK is on the TOP of the boom. NOw insert the $U$ shaped 3/16" rod pieces into the boom from the top through the two sets of one inch holes spaced to accept the rod ends. Install KEEPERS on each rod end as it protrudes from the bottom of the boom. These U clips form attach points for the black Dacron boom support cable installed near antenna completion.

8. ADDING THE BALUNS AND PHASING HARNESS. The BALUN cables are about 3 feet long and the PHASING CABLES are half as long. Attach the baluns first and tighten the connectors GENTLY witl a 7/16" end wrench while holding the body of the connector with a pair of needle nose pliers. This prevents the cable from twisting during installation. Now add the phasing cables as shown in the sketch. Tighten the same as the balun connectors.

9. FINALIZING THE ANTENNA. The main feedline is attached now and routes back to the rear of the boom. USING THE BLACK CABLE TIES provided, form the various cables against the boom and AWAY FROM ELEMENTS. The last tie point for the main feedline should be just about one inch in front of the rear REFLECTOR. and coming away at right angles to it.

10. Position and tighten the BOOM TO MAST PIATE moderately at inches from the rear of the boom and align it with 


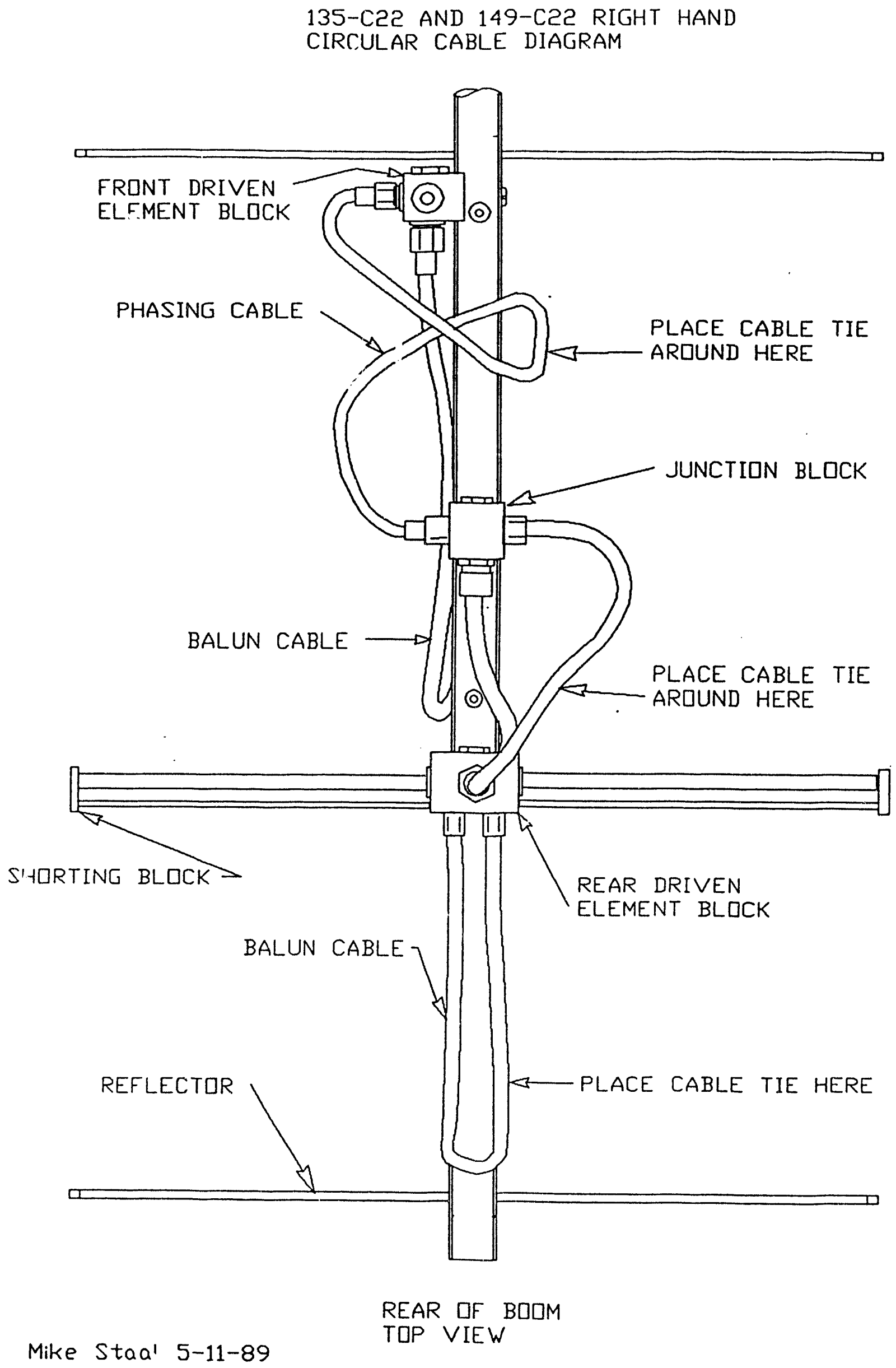


10. Position and tighten the BOOM TO MAST PLATE moderately at inches from the rear of the boom and align it with the forward set of elements. THESE ELEMENTS WILL BE VERTICALLY POLARIZED WHEN THE ANTENNA IS MOUNTED ON THE SUPPORT MAST OR 'H' FRAME.

Install the last $2 " \mathrm{U}$-bolt into the small TURNBUCKLE PLATE and attach the turn buckles. If possible install a short (one foot long or less) temporary mast section through the 2 inch U-bolts in the boom to mast plate and slide on the turnbuckle plate right down against the boom to mast plate ALTERNATELY, temporarily install the turnbuckle U-bolt into the top set of U-bolt holes in the boom to mast plate. This "locks" the alignment of the turnbuckle plate to the boom to mast position. Now attach one end of the BLACK DACRON SUPPORT LINE to the front $U$ clip. Two turns of line and a square knot is adequate and tape the left over end back to the main line to prevent fraying. Route the line back to the forward turnbuckle which should be extended till both threaded ends just protrude into the body of the turnbuckle. Cut the line about a foot past the turnbuckle and attach it to the turnbuckle as on the U clip. Repeat for the rear section of support line. When completed, the two lines should be tight, the turnbuckles ? aying flat out just over the boom and the turnbuckle plate U-bolt CENTERED over the two other U-bolts in the boom to mast plate. When the antenna is installed in a mast, the turnbuckle plate is slid up one foor above the boom and after turnbuckle adjustment, the boom sliould be perfectly straight.

THIS COMPLETES THE ANTENNA ASSEMBLY. THE RECOMMENDED MAST FOR THIS ANTENNA IS TWO INCH DIAMETER 1/4" WALL FIBERGLASS OR EQUIVALENT. DO NOT MOUNT ON A METAL MAST OR RUN THE MAIN FEEDLINE FORWARD AND DOWN ?HE MAST AS THE ANTENNAS VSWR, GAIN AND CIRCULARITY WILL BE DEGRADED.

CAREFULLY MANUFACTURED BY:

M2 ENTERPRISES

7560 N. DEL MAR AV.

FRESNO CA. 93711

209-432-8873 FAX $209 \quad 432-3059$ 


\section{5-C22 ANTENNA}

PART LIST

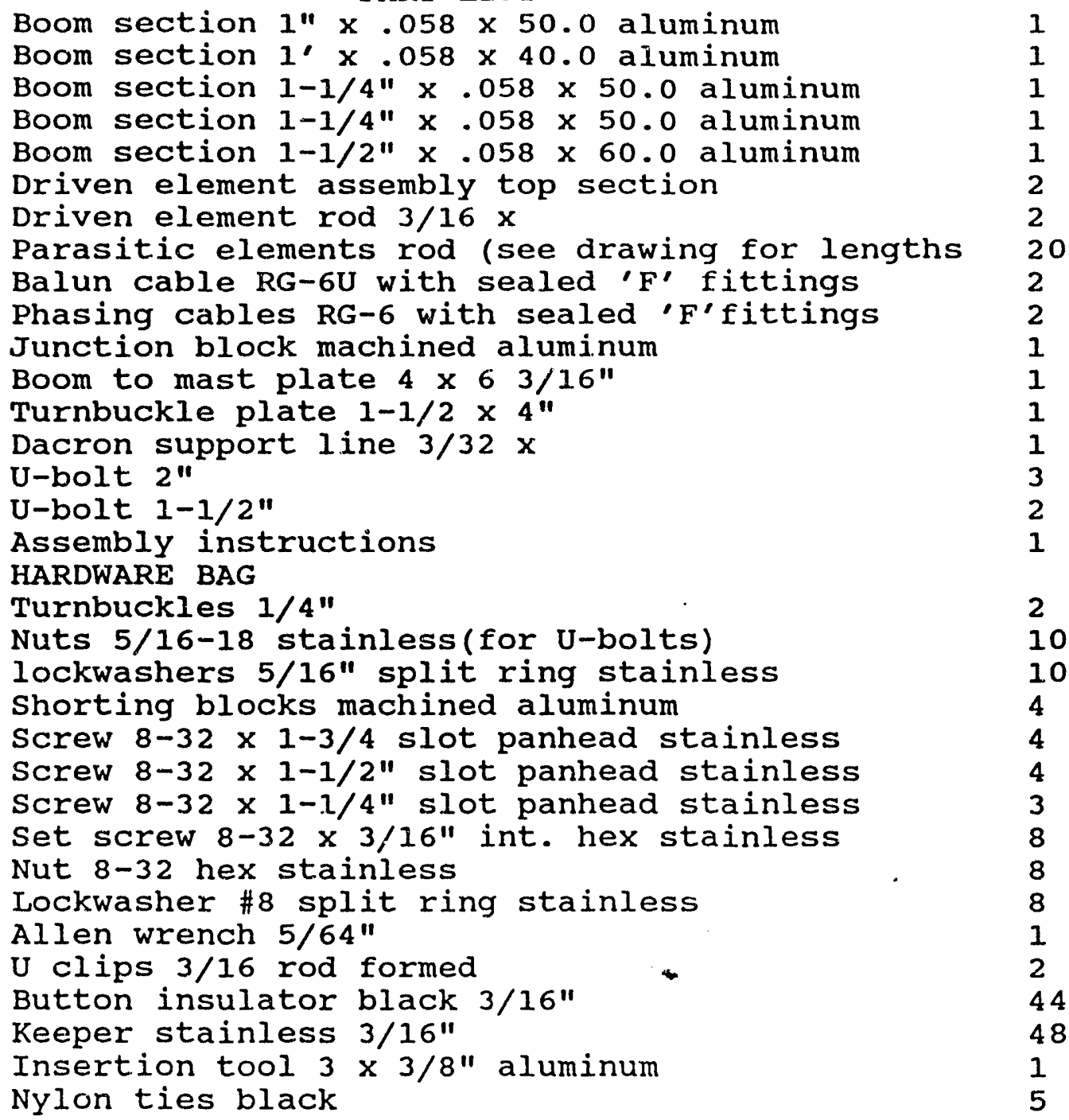




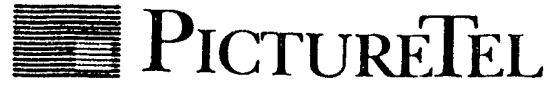

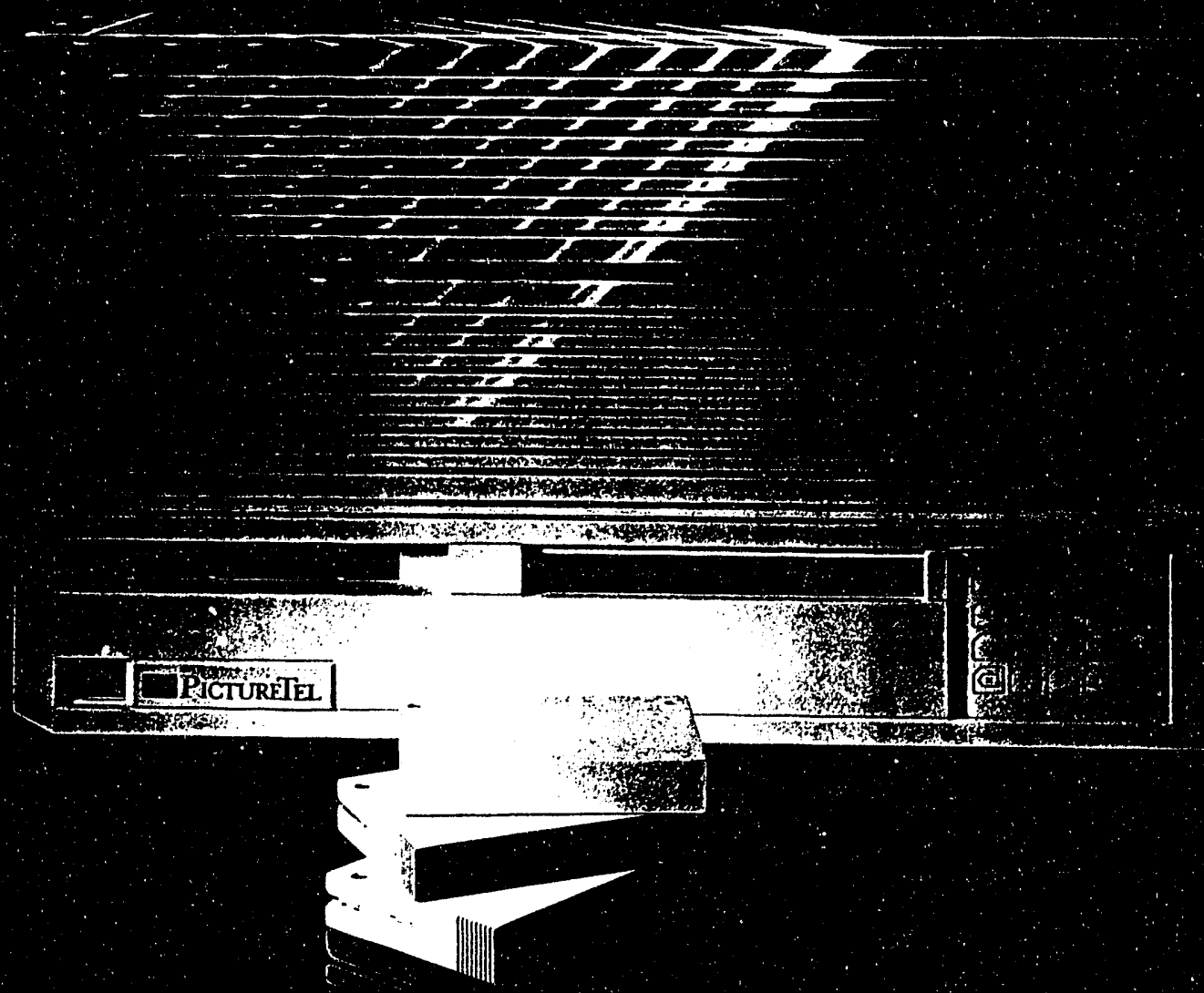

\section{C-3000 VIDEO CODEC}

HIGH-QUALITY MOTION VIDEO

EVEN AT LOW DATA RATES 


\section{C-300O VIDEO CODEC}

The PictureTel C-3000 Video Codec with HVQ ${ }^{\mathrm{TM}}$ (Hierarchial Vector Quantization) and $\mathrm{SG}^{\mathrm{TM}}$ (Software Generation 3) compression software, brings unsurpassed quality at low data rates to videoconferencing users. Operating at transmission speeds ranging from $56 \mathrm{kbit} / \mathrm{s}$ to $2.048 \mathrm{Mbit} / \mathrm{s}$, the $\mathrm{C}-3000$ delivers superior performance to meet virtually all videoconferencing requirements. When connected to switched-56/64 kbit/s

\section{FEATURES}

- Software-based design for long-term, state-of-the-art performance

- $\quad$ HVQ, SG3 and Px64 (optional) algorithm support

- Integrated transmission of video, audio, and data

- Operates on switched-56/64 kbit/s circuits for dial-up convenience or at data rates up to $2.048 \mathrm{Mbit} / \mathrm{s}$ on dedicated networks

- Multipoint capability for videcconferences involving more than two locations simultaneously (optional)

- $\quad$ Freeze-frame videographics for transmission and displaỵ of video and graphics presentations (optional)

- Compatible NTSC and PAL versions for multinational videoconferencing

- $\quad$ Field-proven reliability (30,000 bours MTBF)

\section{Network Adaptability}

Network management is simplified using the C-3000. The C-3000 automatically adjusts its operating rate to match the rate of the selected transmission channel. In addition, when using switched digital services, the C-3000 can be configured to treat two $56 / 64 \mathrm{kbit} / \mathrm{s}$ circuits as one $112 / 128 \mathrm{kbit} / \mathrm{s}$ channel. A terminal control port dial video calls just like ordinary telephone calls at transmission charges comparable to a normal voice call. The $\mathrm{C}-\mathbf{3 0 0 0}$ also operates on private or T-1 digital networks.

The C-3000 is software-upgradeable and, as a result, can accommodate new compression technologies, including the Px64 (H.261) standard. This capability significantly extends the useful life of the $\mathrm{C}-\mathbf{3 0 0 0}$.

easy management of codec functions from the videoconference room location.

\section{Diagnostic Flexibility}

The C-3000 Video Codec has on-screen messaging of system status information which enables simple fault isolation. A built-in control panel supports configuration and diagnostic analyses.

\section{SURVEILLANCE APPLICATIONS}

PictureTel also offers low-cost, one-way configurations of the $\mathrm{C}-3000$ codec for use in situations where remote video and audio surveillance is needed. Using dial-up digitial or private networks, the systems can be used by railroads to view bridges

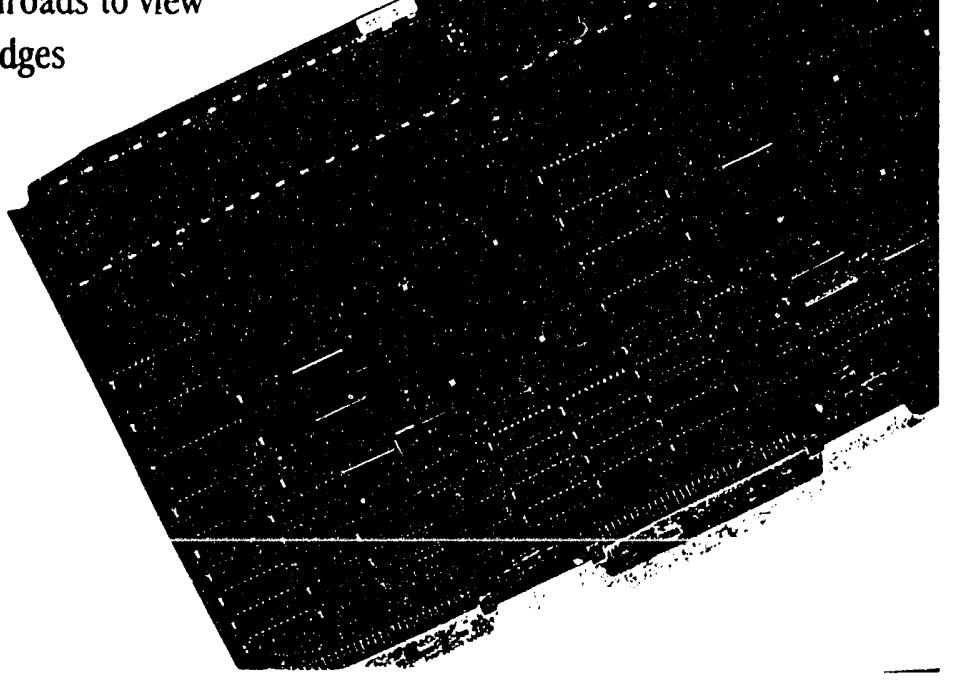


and crossings, businesses to monitor branch stores, hydroclectric plants to watch ice flows, and for many other applications. Remote locations are easily observed without tying up lines or requiring a person at the site.

The surveillance codecs are available in two versions: the C-3000S (send only) and C-3000R (receive only). Both versions also are available with a full-duplex audio option. All the surveillance codecs are based on Picture'Tel's softwareupgradeable C-3000 Video Codec with proprietary HVQ or SG3 image compression technology software or optional Px64 standard software.

\section{PX64(H.261) AND HIGH DATA RATE OPTIONS}

In anticipation of CCITT's adoption of a Px64 videoconferencing standard, software cartridges and a plug-in processor option provide support for Px64 on the C-3000 Video Codec at data rates from $56 \mathrm{kbit} / \mathrm{s}$ to $2.048 \mathrm{Mbit} / \mathrm{s}$. The Px64 software cartridges also include PictureTel's proprietary compression algorithm. The C-3000 automatically selects either the Px64 standard or the proprietary algorithm at call set up. The Px64 and high data rate options for the $\mathrm{C}-3000$ are field-upgradeable.

\section{Link-64}

This low-cost software option provides fully compliant Px64(H.261) support and interoperability for both QCIF (quarter common intermediate format) and Full CIF at data rates ranging from 64 to $384 \mathrm{kbi} / \mathrm{s}$. The video image is captured and displayed at $256 \times 240$ line resolution.

\section{Link-64E}

In addition to a Px64(H.261) software cartridge, the Link-64E option includes a plug-in audio-video interface board that supports QCIF and Full CIF videoconferencing at data rates from 64 to $384 \mathrm{kbit} / \mathrm{s}$ at $352 \times 288$ line resolution.

\section{Link 2.0}

In addition to a Px64(H.261) software cartridge and the audio-video interface board, a plug-in processor upgrade supports Full CIF videoconferencing at data rates from $56 \mathrm{kbit} / \mathrm{s}$ to $2.048 \mathrm{Mbit} / \mathrm{s}$ at $352 \times 288$ line resolution.

\section{W ORLDWIDE SERVICE AND SUPPORT}

First and foremost, PictureTel products are designed for high reliability. However, for preventive maintenance and unexpected problems, PictureTel's Customer Support organization has representatives located throughout the United States. Picture'Tel offers immediate telephone support during business hours, and can provide guaranteed next-day, on-site service support in the continental United States. International support is provided by PictureTel distributors in Western Europe, Australia, Japan and Taiwan. For customers who prefer self-maintenance, PictureTel offers comprehensive technical training courses. 


\section{C-300O VIDEO CODEC SYSTEM SPECIFICATIONS}

\section{COMMUNICATIONS OPTIONS}

- Multipoint support

- Dual channel interface

- Data interface board

\section{VIDEOGRAPHICS OPTION (NTSC OO PAL)}

- Resolution $512 \times 480$

- Average transmission time less than 9 seconds at $112 \mathrm{kbit} / \mathrm{s}$

\section{ENCRYPTION OPTION}

- National Bureau of Standands (NBS) Data Encryption Standard (DES)

- Automatic or manual key entry

- Compatibility with government-approved external cryptographic equipment

\section{PHYSICAL CHARACTERISTICS}

SIZE

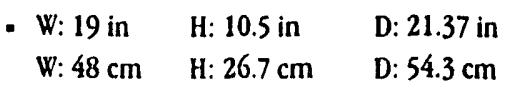

WEIGHT

- $70 \mathrm{lb}, 154 \mathrm{~kg}$

ENVIRONMENTAL

- Ambient temperature $50-104^{\circ} \mathrm{F}, 10-40^{\circ} \mathrm{C}$

- Humidity 15 to $80 \%$ noncondensing

HARDWARE

- Parallel processor architecture

- 240 MOPS (million operations per second) standard

- 320 MOPS with Link 2.0 upgrade

NOISE GENERATION

- Less than $58 \mathrm{~dB} / \mathrm{A} S P L$ at 1 meter

POWER

- North American, European and Asia/Pacific systems available

- 100 to $130 \mathrm{VAC}, 50$ to $60 \mathrm{~Hz}$ operation

- Maximum current 5 Amps $(0.70$ power factor)

VIDEO

- Display resolution at $256 \times 240 ; 352 \times 288$ with Link-64E and Link 2.0 options

- Noise reduction for improved low-light operation

- Automatic synchronization to the video source
- Composite NTSC or PAL input with loopthrough

- Two composite NTSC or PAL outputs

- BNC conneciors for inputs and outputs

AUDIO

- Internal and external audio

- Time synchronization with video

- Internal audio integrated with video

- 3-6.5 KHiz bandwidth

- One high-impedence balanced line-level output

- 5-pin DIN connector for audio inpuv/output

CHANNEL INTERFACE

- Two RS-449 ports, V.35 ports, or X.21 ports

- Two RS-366 dialing ports for ACCUNET Switched-56 compatibility

- 56 to $384 \mathrm{kbil} / \mathrm{s}$ operation

- $384 \mathrm{kbi} / \mathrm{s}$ to $2.048 \mathrm{Mbi} / \mathrm{s}$ operation (optional)

- Automatic adjustment of $\mathrm{C}-3000$ rate to transmission channel rate

\section{USER DATA PORTS}

- Four user-configurable data ports supporting bit synchronous (300 bit/s to $64 \mathrm{kbit} / \mathrm{s}$ ) and byte asynchronous ( $300 \mathrm{bit} / \mathrm{s}$ to $19.2 \mathrm{kbit} / \mathrm{s}$ ) communication protucols using RS-449 and RS-232 or CCITT V.35 interfaces (optional)

- Alternate use of second RS-232 control port as asynchronous data channel ( $300 \mathrm{bi} / \mathrm{s}$ to $19.2 \mathrm{kbi} / \mathrm{s}$ )

\section{FORWARD ERROR CORRECTION}

- Reed-Solomon correction

- Satisfactory operation at error rates of $10^{-5}$ or better

DLAGNOSTICS

- Self-check at power-up

- Run-time diagnostics

SYSTEM MWNAGEMENT/ DLAGNOSTIC DATA PORT

- Front panel keypad and LCD display for configuration and monitoring

COMPRESSION TECHNIQUE

- Programmable

- HVQ, SG3 or PX64

\section{OTHER PICTURETEL PRODUCTS}

PictureTel has pionecred the development and application of videoconferencing as an effective, lowcost business communication tool. Other PictureTel products include:

- C-3000S and C-3000R one-way surveillance codecs

- V-3100 rolłabout videoconferencing system

- V-3100RD rapid deployment videoconferencing system

- V-3235 Videoconferencing System with two 35-inch monitors

- M-7000 Multipoint Bridge and Control System for conducting a single videoconference among up to I6 locations simultaneously

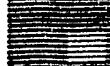 \\ Picturetel CORPORATION}

One Corporation Way, Peabody, MA USA 01960 508.977.9500, FAX 508.977.9481

All specifications subject to change U.L. listed, C.S.A. listed, F.C.C. Class A approved ACCUNET is a Registered Trademark of AT\&T FDG $6 / 90$ 
Pricing for System

Purchase

GOVT.

$\sqrt{0}$

Price and

PURCHASE

Model

PRICE

C3000R

$\$ 12,368 \quad 13,82203 \cdot 2^{6,93}$

C3000S

$\$ 12,368 \quad 13,822$

Software

$\$ 2,550 \quad 5.63$

40000

(One copy required for each codec)

Multipoint Software $\$ 1,658$

(One copy required for each codec if the user wants to send from one site to multiple sites simultaneously)

Encryption Software

(Optional cost per codec)

$\$ 425$

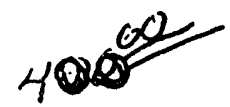

RS449 or V.35 (Must Specify) N/C

Rack Mount or Standalone Mount N/C

(Must Specify)

Shipping

F.O.B. Destination

Installation $\$ 1,500$ Per System - Optional.

Maintenance:

Products include a one year return to factory warranty. On-site services can be provided for an additional fee. For additional information on maintenance options and prices contact Mark Yarish. 


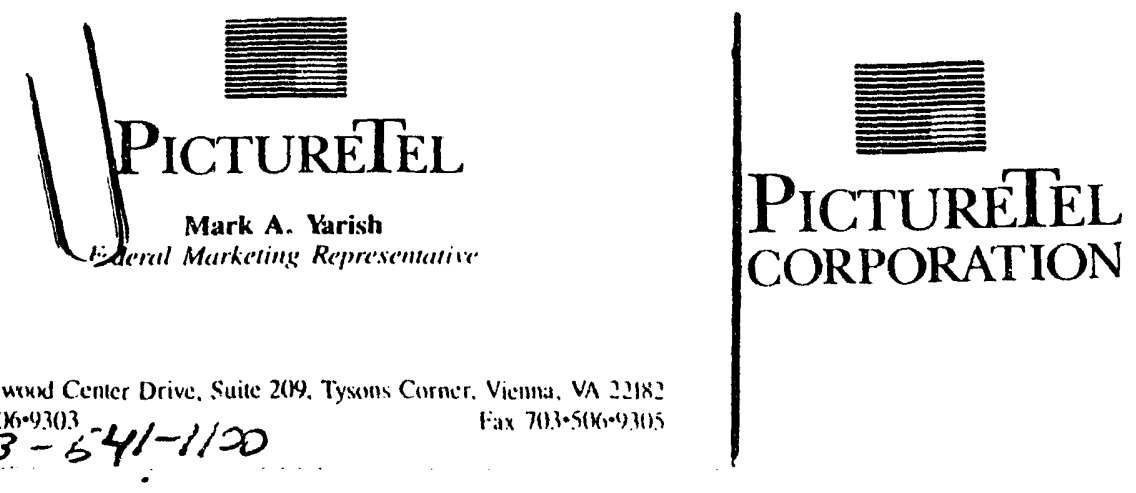

Westurked Center Drive, Suite 2(19. Tyson Corner. Vienna, VA 23IXZ

$=\frac{13 \cdot 5(x \cdot 9) 3(03}{3}-54-1 / 20$

October 7, 1991

VAL.COMM Incorporated

Attn: Mr. Mel Prefer

249 Muriel N.E.

Albuquerque, New Mexico 87123

Dear Mr. Prefer:

As requested I am providing you with Government pricing information for the Picture Tel Model C3000 System.

Should you have any questions or require additional information, please feel free to contact me at (703) 506-9303.

I look forward to working with you.

Sincerely,

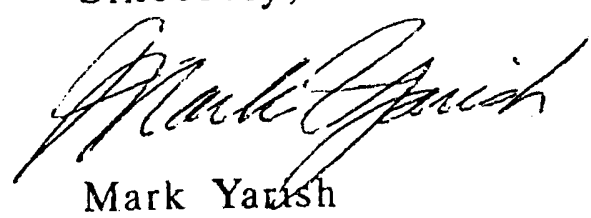

Picture Tel Corporation

1 RECEIVEDCCT 161991. 


\section{ATS3 \\ CONFIGURATION}

\section{OTTO SITE}

\section{EQUIPMENT:}

1. RECEIVE ANTENNA

2. BANDPASS FILTER

3. T/R SWITCH

4. TRANSMIT ANTENNA

5. ACSB TRANSCEIVER

6. TELEPHONE INTERCONNECT

\section{RECEIVE ANTENNA}

The receiving antenna is made up of four 18-element M2 antennas. The receiving antenna has a gain of $18 \mathrm{dBdc}$ and has a circular receive pattern.

2. BANDPASS FILTER

The bandpass filter is comprised of an adjustable preamplifier and 3-bank 6" cavities.

3. T/R SWITCH

The T/R (Transmit/Receive) switch is a Dow Key relay that switches the transceiver from the receive antenna to the transmit antenna. This relay is activated when the microphone PTT(Push To Talk) switch is pushed.

4. TRANSMIT ANTENNA

The transmitting antenna is made up of four 18-element M2 antennas. The transmitting antenna has a gain of $18 \mathrm{dBdc}$ and has a circular transmit pattern.

5. ACSB TRANSCEIVER

The ACSB transceiver is a Stevens Engineering Associates Model SEA175. This unit is a 16-channel mobile transceiver with lower sideband emission of 25 Watts PEP. The transceiver is connected to a Mirage amplifier to increase the power output to a maximum of 80 Watts PEP.

6. TELEPHONE INTERCONNECT

The telephone interconnect is manufactured by Advanced Computer Controls, Inc., and allows a transceiver to be connected to a telephone line for remote control of the transceiver. 


\section{ATS3 - OTTO \\ SITE CONFIGURATION}

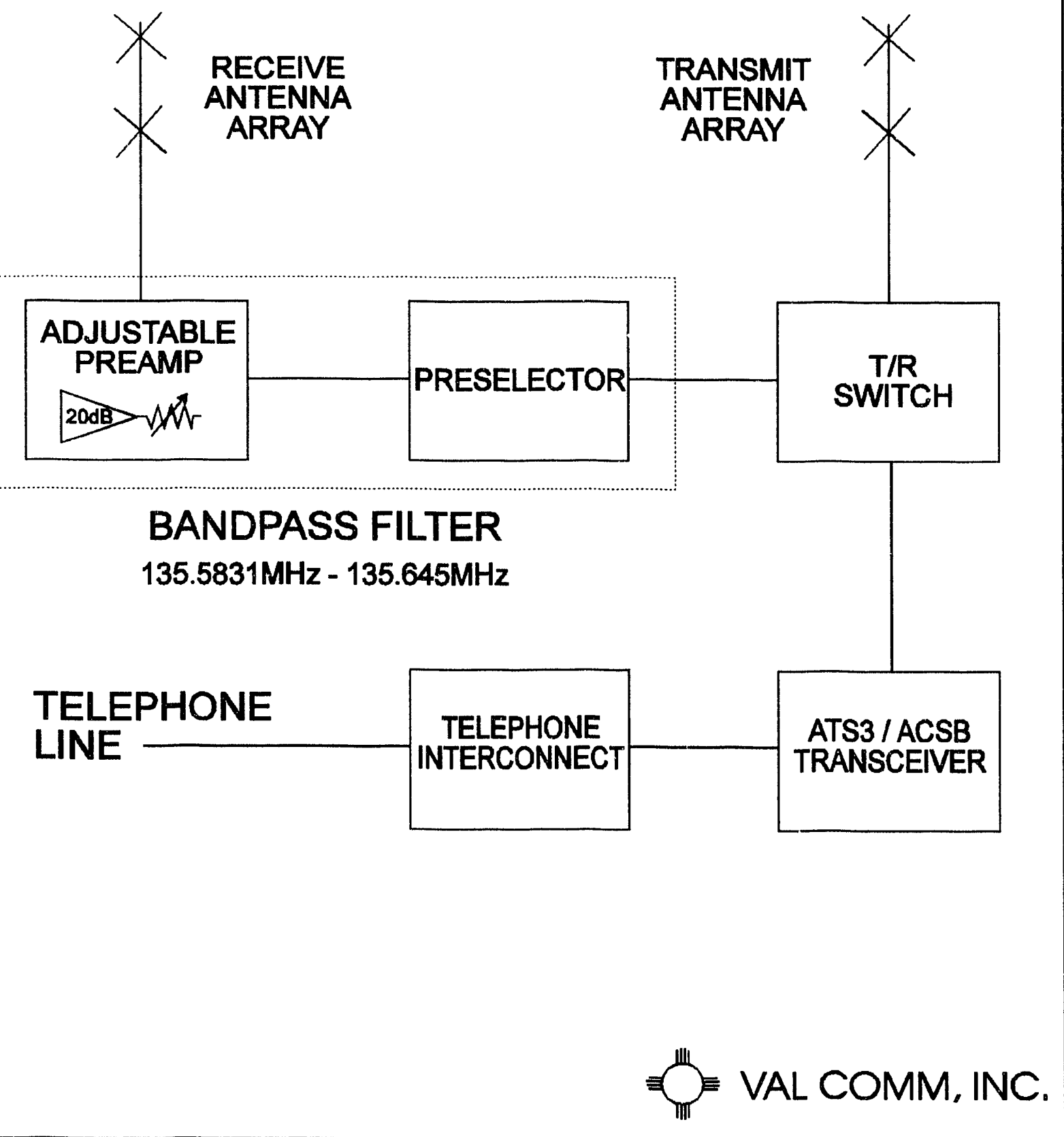




\section{ATS3 ANTENNA ARRAY}

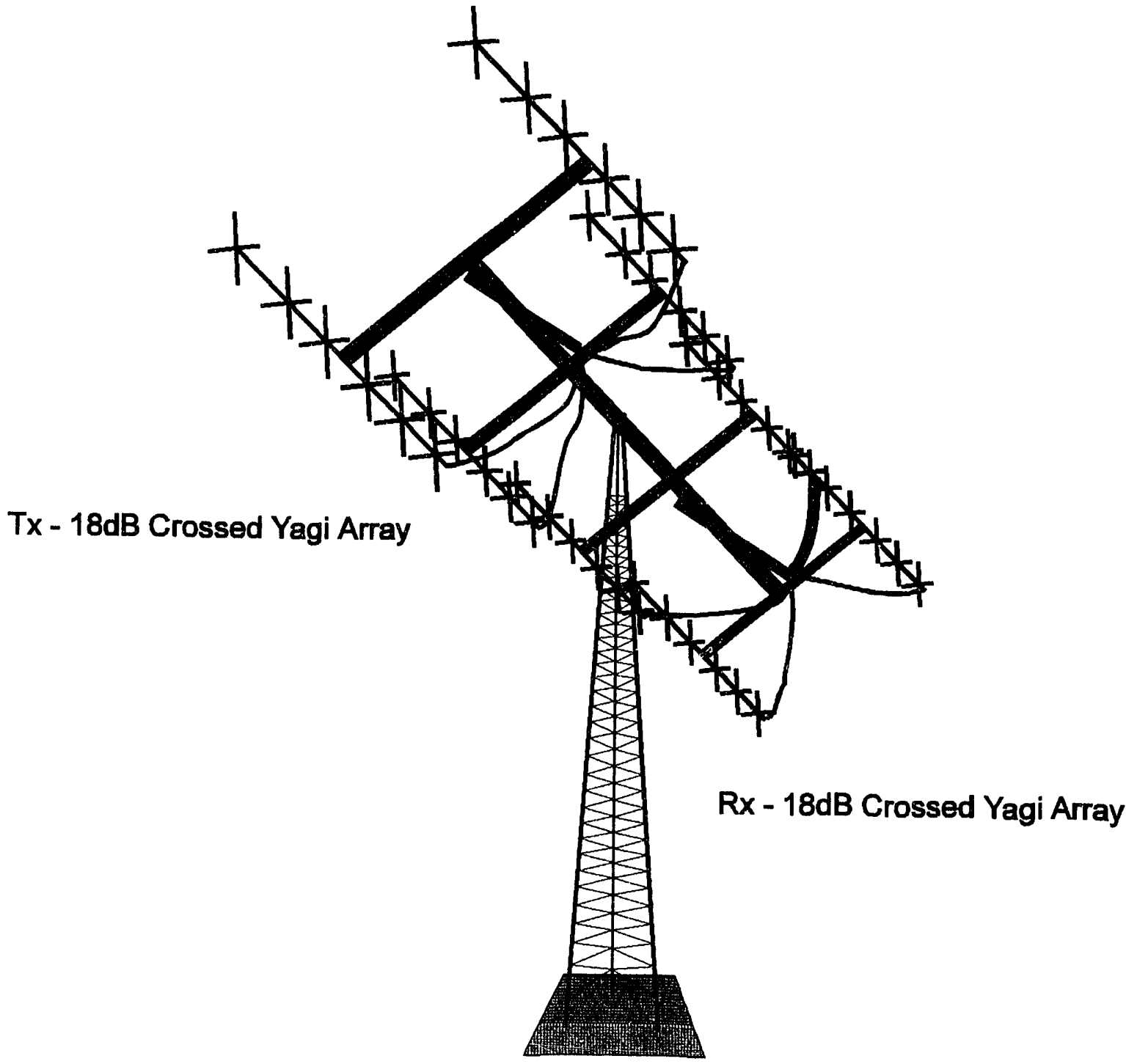

$=\# \equiv$ VAL COMM, INC. 


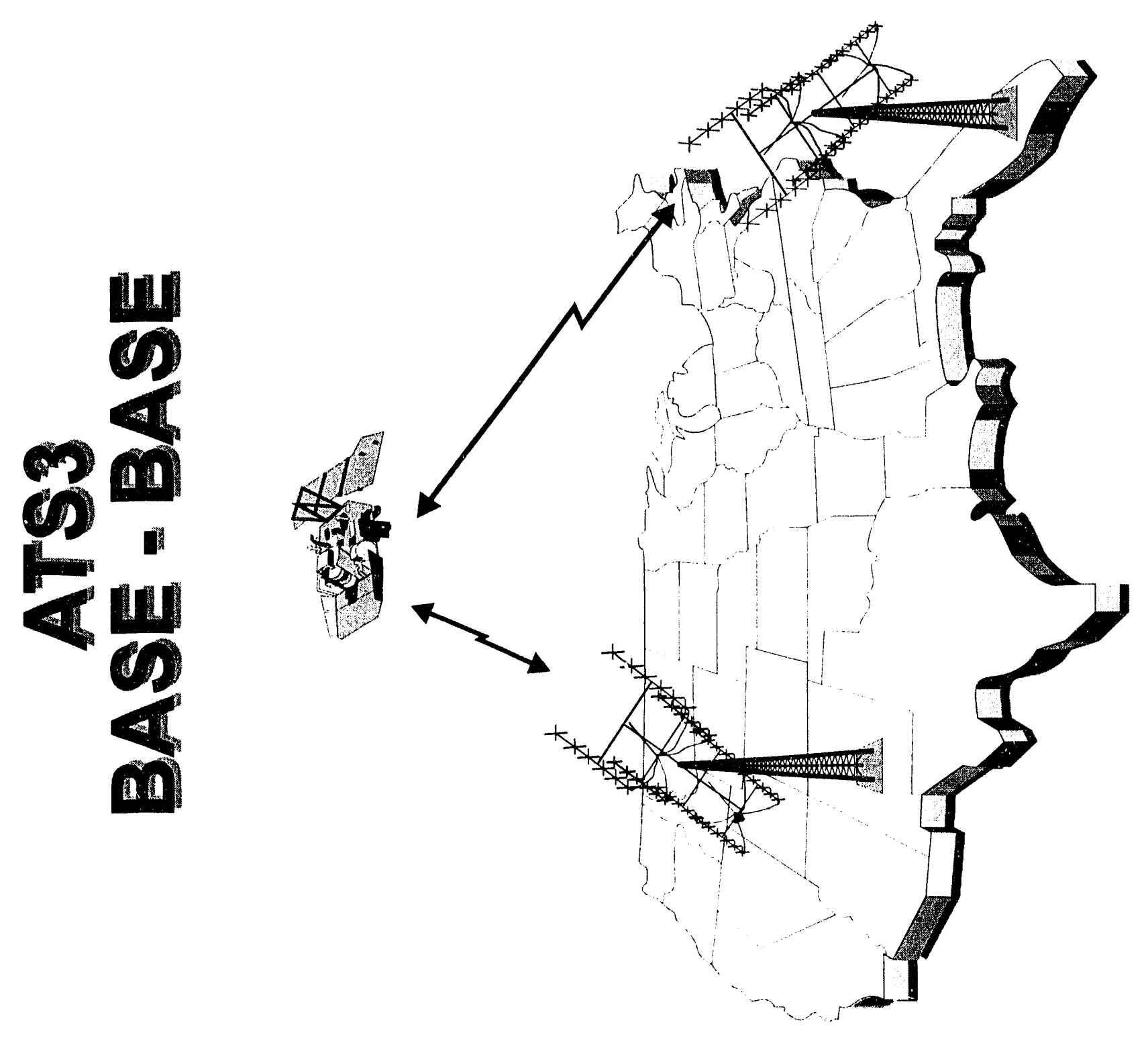

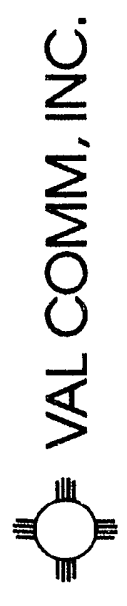




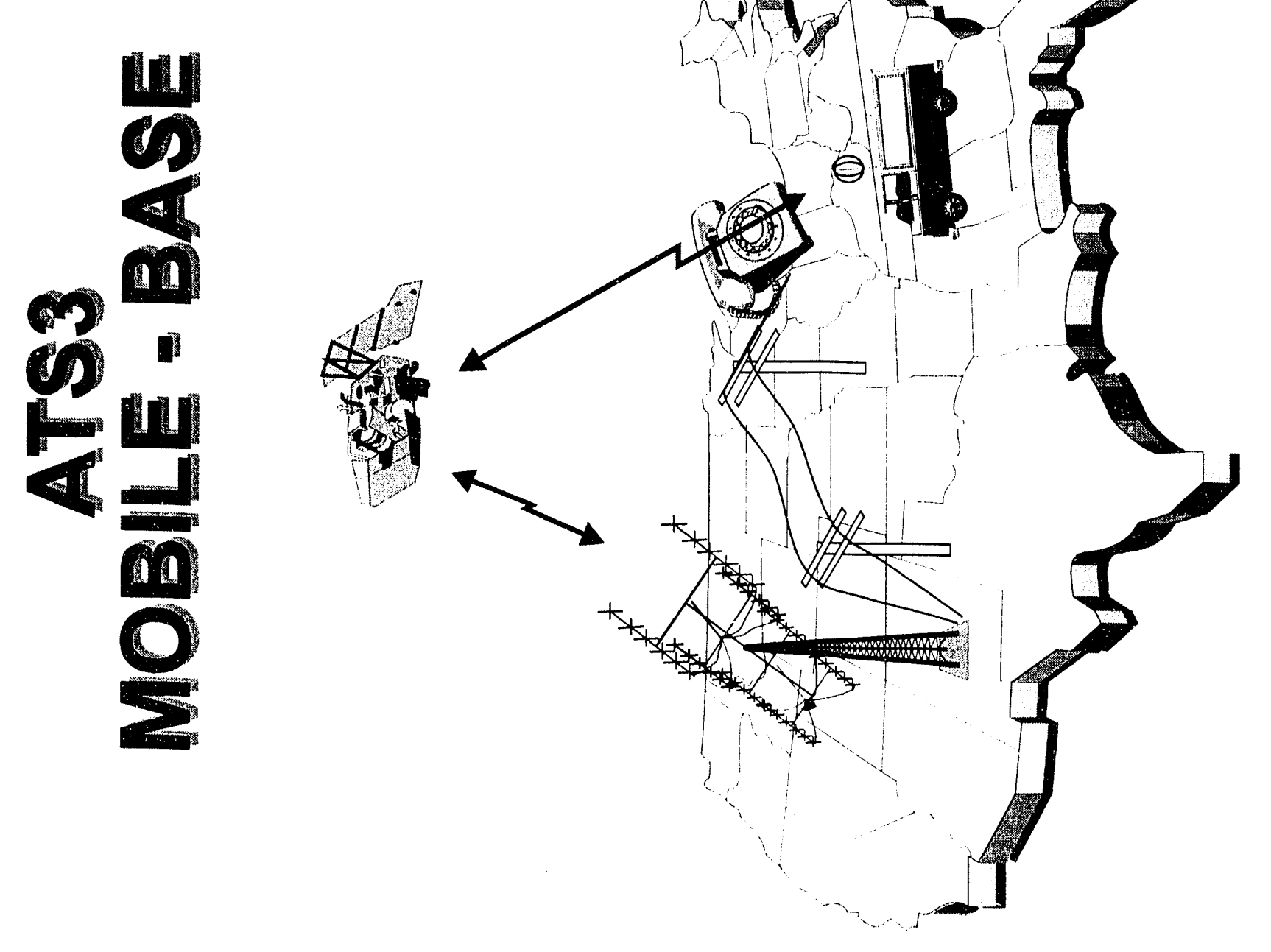




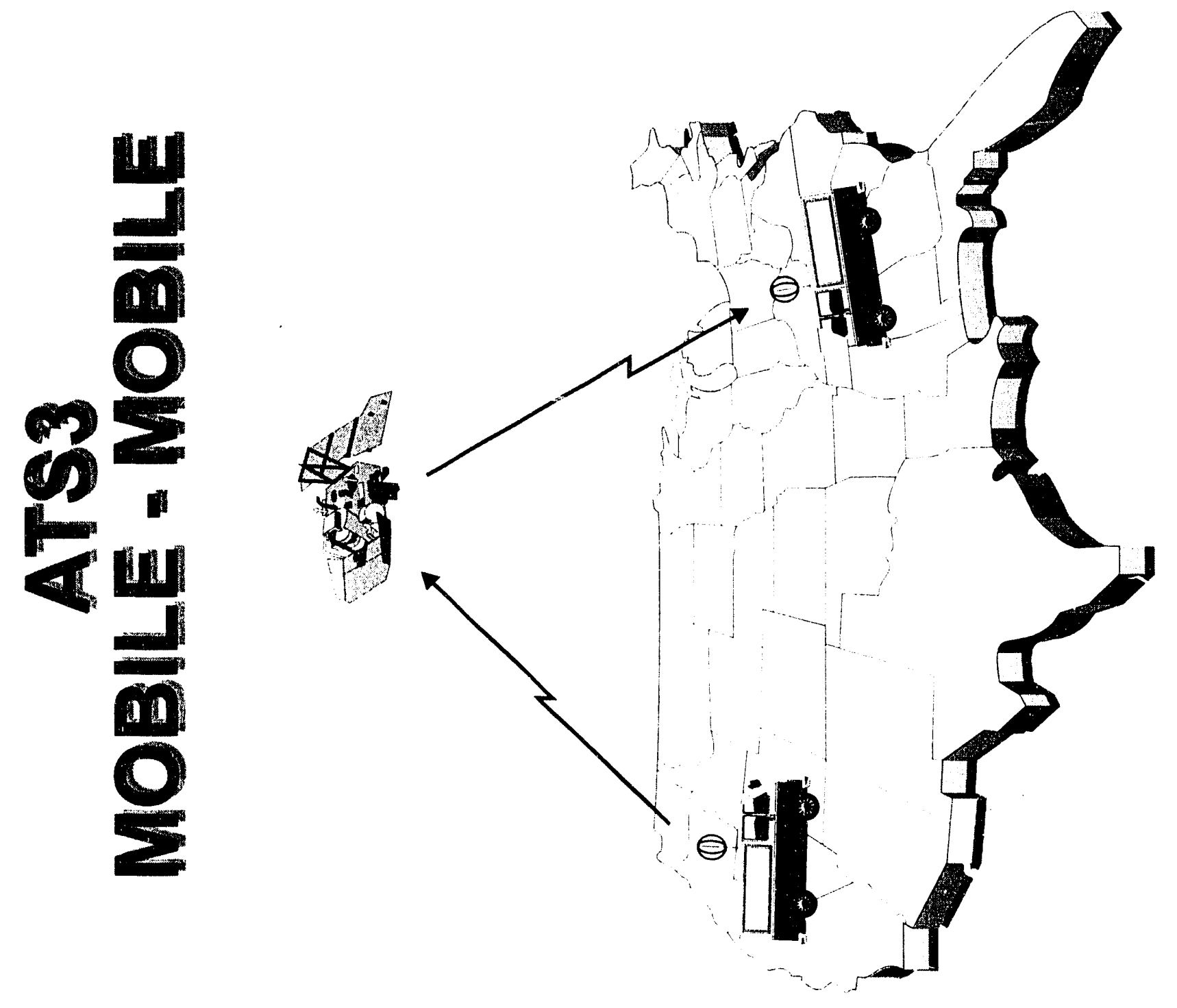

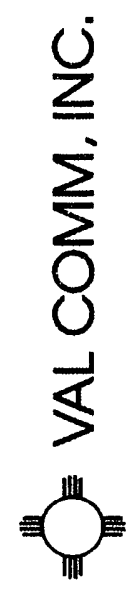


I
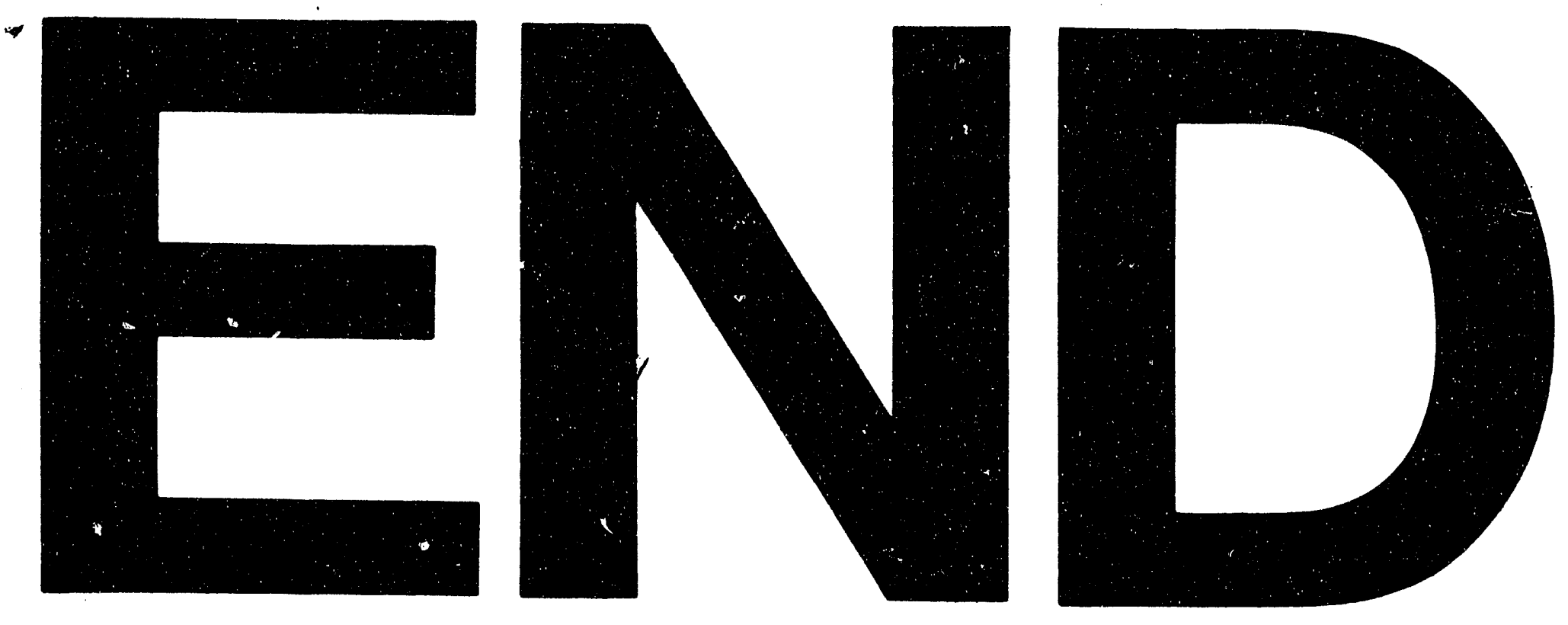

p
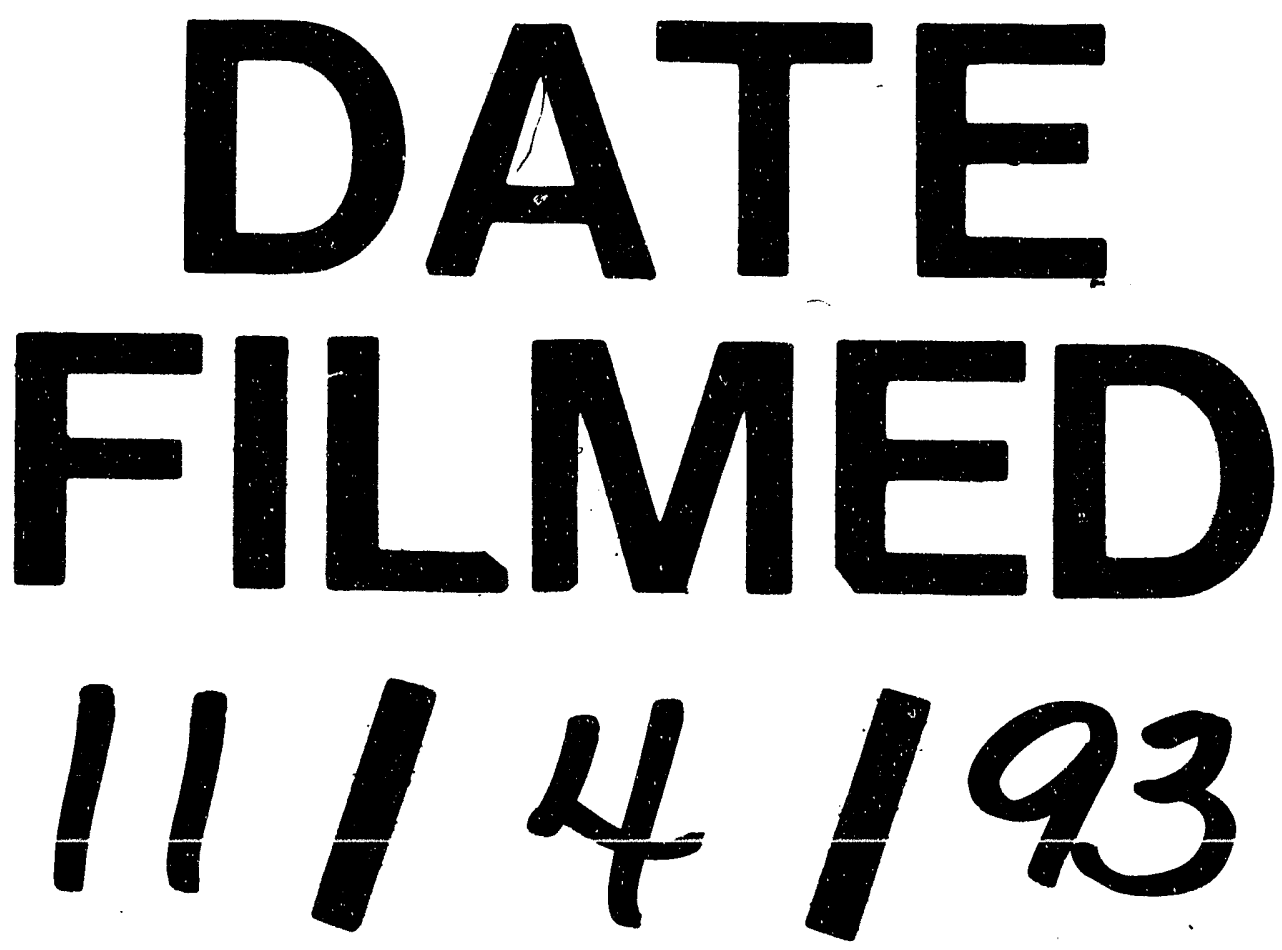
